\title{
VI. Kurze Rückkehr zum Kalten Krieg - Kleine Berlin-Krise und Ende des Prager Frühlings
}

\section{Kiesingers geschickte Isolierungspolitik gegenüber der DDR}

Die Sowjetunion erlaubte der SED im Frühjahr 1968 erneut, die Berlin-Frage zu stellen. Moskau hatte schon zu Beginn des Kalten Krieges versucht, den 1944 zwischen den Alliierten ausgehandelten Status der ehemaligen Reichshauptstadt einseitig zu seinen Gunsten zu verändern. Im Londoner Protokoll vom September 1944 war der Beschluß festgehalten worden, neben den Besatzungszonen ein von allen Mächten zu besetzendes Gebiet Berlin zu schaffen ${ }^{1}$. Die Verwaltung Berlins oblag der Alliierten Kommandantur, die aus den Stadtkommandanten der einzelnen Mächte zusammengesetzt war. Die Kommandantur war dem höchsten Gremium, dem Alliierten Kontrollrat, unterstellt - außerhalb der zonalen Zuständigkeiten der jeweiligen militärischen Oberbefehlshaber. Nach der Kapitulation der Deutschen begann ab dem 1. Juli 1945 die Umgruppierung der durch die Aufnahme Frankreichs in den Rang eines Siegers nunmehr vier Mächte in die vereinbarten Zonen. Im Ausgleich für die drei Berliner Westsektoren - Berlin war von den Sowjets allein besetzt worden - erhielt Moskau jene von britischen und amerikanischen Truppen eroberten Gebiete im Westen der Sowjetzone. Berlin wurde ein von den anderen Zonen getrenntes Gebiet. Zu keiner Zeit hat es zu der sie umgebenden sowjetischen Besatzungszone gehört ${ }^{2}$. Die Westmächte gingen auch künftig davon aus, daß es keine Rolle spiele, wer ein Gebiet als erster besetzt habe. Sie waren 1944/45 der Meinung, daß Deutschland gemeinsam kontrolliert und verwaltet werden müsse. Daher gab es auch keine Vereinbarungen über den Zugang von und nach Berlin zu den westlichen Besatzungszonen.

Aber spätestens im Frühjahr 1947 ließen sich die unterschiedlichen politischen und gesellschaftspolitischen Vorstellungen der Siegermächte nicht mehr in Einklang bringen ${ }^{3}$. Mit dem Ende der Verständigung über Deutschland wurde auch die interalliierte Verwaltung über Berlin eingestellt. Wenige Wochen nach dem Auszug der Sowjets aus dem Kontrollrat verließ der sowjetische Beauftragte am 16. Juni 1948 die Kommandantur. Eine Woche später verhängte Moskau eine Blockade aller Land- und Wasserwege zwischen Berlin und den Westzonen. Die Sowjetunion wollte durch diese drastische Maßnahme die Westmächte aus der früheren deutschen Hauptstadt hinausdrängen ${ }^{4}$. Aber sie unterschätzte den Durchhaltewillen der West-Berliner Bevölkerung ebenso wie den der

\footnotetext{
1 Vgl. Steininger, Deutsche Geschichte, Band 1, Protokoll zwischen den Vereinigten Staaten, dem Vereinigten Königreich und der Sowjetunion betreffend die Besatzungszonen in Deutschland und die Verwaltung von Groß-Berlin, 12.9.1944, S. 39.

2 Vgl. Mahncke, Das Berlin-Problem, S. 657; Wetzlaugk, Berlin und die deutsche Frage, S. 21.

3 Vgl. Loth, Die Teilung der Welt.

4 Vgl. Benz, Die Gründung der Bundesrepublik, S. 11 ff.; Graml, Die Alliierten und die Teilung Deutschlands, S. 207; Mahncke, Das Berlin-Problem, S. 659; ders., Berlin im geteilten Deutschland, S. 43; Wettig, Aktionsmuster, S. 325. Zwar hatten die Sowjets die Blockade mit der Währungsreform in den westlichen Zonen gerechtfertigt, aber in der Geschichtsschreibung ist man sich darüber einig, daß es ihnen vorrangig um den Abzug der Westmächte ging. Wetzlaugk (Berlin und die deutsche Frage, S. 51) behauptet, die Sowjetunion habe den deutschen Weststaat verhindern wollen. Ähnlich beurteilt dies Smith (Clay, S. 465): Die Russen hätten das französische Zögern beobachtet, in die Bizone einzutreten, und wollten den Westen auseinanderbringen.
} 
drei Mächte. Es gelang über die Luftbrücke, die drei Westsektoren Berlins mit dem Notwendigsten zu versorgen. Die Sowjets gaben im Mai 1949 die Blockade auf. Sie hatten weder erreicht, daß sich der Zusammenschluß der westlichen Zonen zur Bundesrepublik verzögerte, noch die Siegermächte gezwungen, Berlin zu verlassen. Statt dessen wurde das Verhältnis zwischen den Deutschen und den Westmächten durch die Hilfsaktionen gefestigt und die Westintegration der Bundesrepublik beschleunigt. In dem zwischen den UN-Delegierten beider Supermächte, Philip C. Jessup und Jakob Malik, ausgehandelten Abkommen wurde der Status quo vom 1. April 1948 wiederhergestellt. Er schloß erstmals auch den deutschen Zivilverkehr mit ein. Allerdings duldeten die Westmächte, daß dieser Verkehr im Gegensatz zur Durchfahrt des Militärs Kontrollen unterworfen wurde 5 . Die Sowjetunion verweigerte jedoch die weitere Behandlung Berlins als Einheit, wie es die Westalliierten forderten. Schon vor der Blockade hatte sie im Osten der Stadt eine eigene Stadtverwaltung eingesetzt. Im Jahre 1949 erklärte sie sich nur unter der Voraussetzung zur Behandlung Berlins als Einheit bereit, wenn ihr ein Vetorecht - auch in den Westsektoren - eingeräumt werden würde. Dazu konnten sich Amerikaner, Briten und Franzosen nicht verständigen, und so blieb ein Rest der gemeinsamen Kontrolle nur durch die existierende Freizügigkeit innerhalb des Stadtgebietes erhalten. Aufgrund der Grenzschließung im Sommer 1952 war Berlin der einzigen Ort in Deutschland, wo Menschen aus dem Ost-Sektor und der DDR zusammentreffen konnten. Damals war ihnen bereits der Besuch der DDR untersagt worden. Der Mauerbau am 13. August 1961 setzte dem dann ein Ende und machte für zur Flucht entschlossene Ostdeutsche dieses Schlupfloch dicht.

Mit der Bildung von Bundesrepublik und DDR wurde versucht, die Berliner Teile dem jeweiligen Staat einzugliedern. Die Besatzungsmächte förderten diese Entwicklung in gewissem Maße, die Westmächte mit deutlichem, die Sowjets mit weniger klarem Vorbehalt. Im Parlamentarischen Rat und im Bundestag durften West-Berliner nicht als stimmberechtigte Mitglieder teilnehmen. Die Westmächte beharrten auf ihrer Ansicht, daß Berlin kein Land der Bundesrepublik sei und nicht von der Bundesregierung gelenkt werden dürfe ${ }^{6}$. Bundesgesetze galten in Berlin nicht Kraft der Autorität des Bundestages, sondern aufgrund von Übernahmegesetzen. Gesetze über Verteidigungsangelegenheiten hatten ebenso keine Geltung in Berlin. Auch als das Bundesverfassungsgericht die KPD in der Bundesrepublik verbot, blieb in Berlin die Sozialistische Einheitspartei WestBerlin (SEW) bestehen. Die Besatzungsmächte behielten sich ein Vetorecht vor, das erst am 3. Oktober 1990 erlosch. Wenn Berlin in internationale Verträge einbezogen werden sollte, mußte die Bundesregierung die Mächte vorher um ihre Zustimmung bitten. Als die Bundesrepublik 1955 souverän wurde, sicherten sich die Alliierten ausdrücklich im Vertragstext die Besatzungsgewalt über Berlin’.

5 Vgl. Riklin, Das Berlinproblem, S. 395 ff.; Gablentz et al. (Hrsg.), Dokumente zur Berlin-Frage.

6 Siehe Schwartz, America's Germany, S. 64; McCloy wollte sich für Berlin als 12. Bundesland der Bundesrepublik einsetzen, aber sowohl die Franzosen wie auch Bundeskanzler Adenauer waren gegen diesen Plan; vgl. auch Schwarz, Adenauer, Der Aufstieg, S. 679 ff., und Wetzlaugk, Berlin und die deutsche Frage, S. 127.

7 Vgl. Steininger, Deutsche Geschichte, Deutschlandvertrag vom 23.10.1954, Band 2, S. 403 f.; im Artikel 2 heißt es: „Im Hinblick auf die internationale Lage, die bisher die Wiedervereinigung Deutschlands und den Abschluß eines Friedensvertrags verhindert hat, behalten die Drei Mächte die bisher von ihnen ausgeübten oder innegehabten Rechte und Verantwortlichkeiten in bezug auf Berlin und Deutschland als Ganzes einschließlich der Wiedervereinigung Deutschlands und einer friedensvertraglichen Regelung." 
Die Sowjetunion verfuhr mit Ost-Berlin auf ähnliche Weise, wenn auch mit geringerer Entschlossenheit. Zunächst wurde Ost-Berliner Volkskammerabgeordneten das Stimmrecht verweigert, aber als die Sowjetunion der DDR die Souveränität übertrug, verzichtete Moskau auf einen Vorbehalt. Lediglich in einer Erklärung vom 27. März 1954 behielt es sich Funktionen vor, die „sich aus den Verpflichtungen ergeben, die der UdSSR aus den Vier-Mächte-Abkommen " erwüchsen ${ }^{8}$. In den folgenden Jahren gab die UdSSR allerdings zunehmend ihre Vorbehalte auf. Nach der Übertragung des DDR-Wehrpflichtgesetzes auf das Stadtgebiet blieben nur noch „völlig bedeutungslose Residuen des früheren Rechtsstatus" übrig9.

Nachdem die Bundesrepublik die Souveränität erworben hatte, wurde dort seit 1955 verstärkt der Wunsch geäußert, West-Berlin solle Hauptstadt und Regierungssitz werden. Damit sollten der Wille und die Entschlossenheit zur Wiedervereinigung der deutschen Staaten dokumentiert werden. Die Bewegung richtete sich gegen die Konsolidierung des Status quo durch die Integration beider deutscher Staaten in das jeweilige Bündnissystem. Der Vorschlag erhielt den Beifall aller Parteien im Bundestag, nur die Bundesregierung lehnte ab und verwies auf den Tatbestand, daß sie in keiner Stadt regieren könne, über die sie nicht volle Souveränität besitze. Immerhin kam im Februar 1957 ein Bundestagsbeschluß zustande, der die stufenweise Vorbereitung Berlins zur Übernahme der Hauptstadtrolle am Tag der Wiedervereinigung empfahl. Das war der Beginn für den konzentrierten Aufbau der Bundespräsenz durch die Verlegung von Bundesbehörden in den Westteil ${ }^{10}$. Etwa zur gleichen Zeit kam das Bundesverfassungsgericht zu dem Ergebnis, West-Berlin sei ein Land des Bundes. Diese Ansicht habe sich immer mehr Bahn gebrochen, urteilte das Organ, und allein die aufrechterhaltene Besatzungsgewalt verhindere die de jure-Mitgliedschaft des Landes im Bund ${ }^{11}$.

Vor diesem Hintergrund startete der Generalsekretär der KPdSU im November 1958 einen zweiten Versuch, die Lage Berlins zum Vorteil der UdSSR zu verändern. Chruschtschow, seit dem 31. März 1958 auch Ministerpräsident der Sowjetunion, nutzte die scheinbar günstige Gelegenheit: Nach dem großen Erfolg des Sputnik-Starts schien Moskau Washington nicht nur technologisch überholt zu haben, sondern auch militärisch überlegen zu sein. In Noten an die drei Westmächte hieß es jetzt, die Londoner Vereinbarungen über Berlin seien außer Kraft gesetzt, und daher schlage er, Chruschtschow, vor, die „unrechtmäßige“ Besatzung West-Berlins zu beenden, die Stadt zu entmilitarisieren und in eine „selbständige politische Einheit“ - eine „Freie Stadt“ - umzuwandeln. Als Alternative nannte er eine Besetzung durch die Vier Mächte, was auf das schon vorher geforderte Vetorecht der Sowjets über den Westteil der Stadt hinauslief, oder durch Streitkräfte der Vereinten Nationen. Für den Fall, daß die Westmächte nicht auf den Vorschlag eingingen, drohte Chruschtschow den Abschluß eines separaten Friedensvertrages mit der DDR an. Die Rechte und Pflichten der Sowjetunion für den Zugang nach Berlin würden dann - das war der Kernpunkt der Drohung - der DDR übertragen werden ${ }^{12}$.

\footnotetext{
8 Weber (Hrsg.), DDR, Erklärung der Regierung der DDR zur Souveränität vom 27.3.1954, S. 213.

9 Wettig, Aktionsmuster, S. 327. Mahncke (Das Berlin-Problem, S. 659) vertritt die gegenteilige These und behauptet, daß die Sowjets den Viermächte-Status im Gegensatz zur politischen Führung der DDR offenhalten wollten und weiter offenhielten.

10 Vgl. Wetzlaugk (Berlin und die deutsche Frage, S. 123), der zudem von einem Wendepunkt spricht, "weil die Debatten und ihr Ergebnis die Grenzen der deutschlandpolitischen Initiativen markierten und einmal mehr offenlegten, wie die Chancen, die aus der einmaligen Lage Berlins zu erwachsen schienen, durch die große Empfindlichkeit des Exponenten konterkariert wurden". $11 \mathrm{Vgl}$. Mahncke, Berlin im geteilten Deutschland, S. 63 f.

12 Vgl. Riklin, Das Berlinproblem, S. 190; siehe auch Wetzlaugk (Berlin, S. 152) zu den Zielen der Sowjets.
} 
Zunächst ließen die Westmächte, insbesondere die USA, eine gewisse Bereitschaft zu Verhandlungen erkennen, aber glücklicherweise brach der Kontakt zwischen den ehemaligen Alliierten ab, als Chruschtschow 1960 die Pariser Gipfelkonferenz platzen ließ. Mehrere Ultimaten verstrichen, ohne daß etwas geschah. Mit dem Bau der Mauer im August 1961 war der Höhepunkt der Krise erreicht. Bis dahin kamen immer größere Menschenmengen - an manchen Tagen im August 1961 waren es über 20000 - nach WestBerlin. Die Mauer machte dem Flüchtlingsstrom ein Ende. Als im Herbst 1962 die Amerikaner den Aufbau von russischen Raketen auf Kuba mit einer Seeblockade beantworteten, stimmte der Generalsekretär einem Geschäft zu: Abzug russischer Raketen von Kuba gegen den Abzug amerikanischer Raketen aus der Türkei. Damit war nicht nur die Kuba-Krise beendet. Moskau verfolgte nun eine andere Strategie in Berlin. Künftig vermied man Angriffe auf die Präsenz der Westmächte ${ }^{13}$, dafür schoß man sich auf die Bundesrepublik ein. Die DDR übernahm dabei mehr und mehr selbst die Initiative der Kampagne, die aber von Moskau jeweils unterstützt und auch verstärkt wurde. Das Ziel bestand offensichtlich darin, Differenzen zwischen den Westmächten und der Bundesrepublik entstehen zu lassen ${ }^{14}$. Im Freundschafts- und Beistandsvertrag zwischen der DDR und der Sowjetunion von 1964 versprach man sich, „West-Berlin als selbständige politische Einheit betrachten“ zu wollen. Schließlich wurde eine Berliner Plenarsitzung des Bundestages im April 1965 erstmals durch massive Störmaßnahmen begleitet. Über Berlin durchbrachen Düsenflugzeuge die Schallmauer und verursachten einen Lärm, der bis zu den Abgeordneten vordrang.

\section{Sowjetische Berlin-Politik in der Zeit der Großen Koalition}

Während die SED auch weiterhin die Kampagne für die „selbständige Einheit WestBerlin" schürte, interessierte sich der Kreml im Jahre 1966 zunächst nicht für das Berlinthema. Gegen Ende des Jahres wirkte er zunächst sogar darauf hin, die DDR zu zügeln. Exponierte Ansprüche und Festlegungen der DDR unterblieben; Ulbricht sprach auf dem 23. Parteitag der KPdSU kein Wort über West-Berlin ${ }^{15}$. Die Schonung

13 Vgl. Mahncke, Das Berliner-Problem, S. 661 f.; der Sowjetunion schien klar geworden zu sein, meint Mahncke, daß der Westen entschlossen war, die Vorstöße in Berlin abzuweisen, und „daß er dort, wo als vital erachtete Interessen betroffen waren, auch ein militärisches Risiko einzugehen bereit war". Hillgruber (Europa in der Weltpolitik, S. 102) spricht vom "Kuba-Desaster", das Moskau zwang, zu einer mittelfristigen Entspannung überzuleiten; Wettig (Aktionsmuster, S. 329) meint, daß die Erfahrungen einer offensiven Berlinpolitik die Sowjets zu einer veränderten Einschätzung ihrer Politik führten. Anstatt den Westen zu verunsichern und auseinanderzudividieren, hätten die sowjetischen Vorstöße die Westmächte und die Bundesrepublik enger zusammenrücken lassen und damit einen Widerstand hervorgerufen, den sie nicht hatte überwinden können. Zu Recht verweist Griffith (Ostpolitik, S. 102 f.) auf die offensichtlichen Fehlkalkulationen der Sowjets; Chruschtschow habe jedes Angebot ausgeschlagen, anstatt darauf einzugehen. Er hätte viel erreichen können: eine internationale Zugangsbehörde, wie sie die Amerikaner vorgeschlagen hatten; Beschränkungen der westlichen Truppen und der Propagandaaktivitäten; auch eine von West- und Ostdeutschen gemeinsam besetzte Zugangsbehörde hätte Verhandlungsgegenstand sein können. Sein Beharren auf Maximalforderungen habe Chruschtschow um diese Zugeständnisse gebracht.

${ }^{14} \mathrm{Vgl}$. Wettig (Aktionsmuster, S. 329), der darauf hinweist, daß die UdSSR versteckt gegen die Präsenz der Westmächte argumentierte, wenn ihre Propaganda von der „Unterwerfung “ West-Berlins unter die Amerikaner oder gegen die angeblichen Machenschaften der „NATO-Aggressoren" in der Stadt und gegen den "Mißbrauch" der westlichen Präsenz für die "revanchistischen“ Ziele der westdeutschen West-Berlin-Politik sprach.

15 Vgl. Wettig, Ost-Berlin im Schatten, S. 267. 
hielt an bis Ende Dezember 1967. Gerhard Wettig behauptet, die Sowjetunion habe darauf gehofft, daß sich mit der Großen Koalition auch eine Umorientierung Bonns - weg von der atlantischen, hin zur französischen Bindung - vollziehen werde. Vor allem die Übernahme wichtiger Regierungspositionen durch sogenannte „Gaullisten“ wie Strauß und später auch Guttenberg habe diese Hoffnung bei den Sowjets genährt. Auch bei den Sozialdemokraten glaubte man im Kreml Tendenzen entdeckt zu haben, die auf eine neue Orientierung hindeuteten ${ }^{16}$. Nach dieser These habe die Sowjetunion die Bundesregierung solange geschont, bis durch eine Nato-Tagung im Dezember 1966 klargeworden sei, daß sich an der bisherigen Loyalität Bonns gegenüber Washington nichts ändern werde.

Da die Große Koalition durch ihre Ostpolitik auf einige osteuropäische Länder Eindruck gemacht hatte, verschärfte Moskau jetzt seine Propaganda gegen die Bundesrepublik. Auch die verbalen Angriffe auf West-Berlin nahmen wieder zu. In der Karlsbader Deklaration vom 26. April 1967 wurden der Bundesrepublik „provokatorische Ansprüche gegenüber West-Berlin" vorgeworfen; die politische Einheit West-Berlin solle, so wurde gefordert, ihr Verhältnis zur DDR normalisieren ${ }^{17}$. Der Status quo in Europa sei durch die „westdeutschen Revanchisten“ bedroht. Diese hätten ein mehrstufiges Annexionsprogramm entworfen und wollten sich nun Stück für Stück West-Berlin, die DDR, weite polnische, tschechoslowakische und sowjetische Gebietsteile unter den Nagel reißen. Die Sowjetunion entwickelte eine Domino-Theorie für Osteuropa und erklärte, mit Berlin falle der erste Stein ${ }^{18}$. Es ging den Sowjets darum, ihre „Verbündeten“ bei der Stange zu halten: Sie sollten sich von den Klängen aus dem Westen nicht becircen lassen. Hinter dem friedlichen Ton der Ostpolitik verberge sich der aggressive Charakter der "westdeutschen Revanchisten“, hieß es. Aber im Jahre 1968 beschränkte sich Moskau nicht mehr darauf, Bonn rhetorisch auf die Anklagebank zu setzen. Die Sowjets ließen die DDR erstmals "Gegenmaßnahmen“ ergreifen. Der SED war West-Berlin seit langem ein Dorn im Auge. Ulbricht drängte die Kremlführung, dem Besatzungsstatus ein Ende zu machen ${ }^{19}$. Der Generalsekretär schien bereit, für dieses Ziel auf die schwache Stelle, den Transitverkehr, zu zielen. Am 1. Dezember 1967 brachte er vor der Volkskammer die Sache ins Rollen. Zum Status des Stadtteils erklärte er: $\mathrm{Da}$ West-Berlin auf dem Territorium der Deutschen Demokratischen Republik liege und rechtlich zu ihr gehöre, aber zur Zeit einem Besatzungsregime unterworfen sei, gelte bis auf weiteres der Vertrag zwischen der DDR und der Sowjetunion vom 12. Juni 1964. Damit unterstrich Ulbricht den Willen, West-Berlin auf den Status einer unabhängigen dritten deutschen Einheit festzulegen. Die Volkskammer und die Regierung der DDR würden sich unablässig dafür einsetzen, so fügte der Parteichef drohend hinzu, Schritt um Schritt auch die letzten Überreste des Zweiten Weltkrieges zu beseitigen. Wenig später erklärte Außenminister Otto Winzer im finnischen Rundfunk, die Regierung der DDR sei jederzeit bereit, mit dem Berliner Senat einen Vertrag über den unabhängigen Status von West-Berlin abzuschließen. Winzer lockte mit vielfältigen Möglichkeiten für vertragliche Regelungen auf den Gebieten des Handels, der Wirtschaft, des Verkehrs und der Kultur ${ }^{20}$.

16 Vgl. ebenda, S. 265; Griffith, Ostpolitik, S. 141; Larrabees, The Politics of Reconciliation.

17 EA 22 (1967), Folge 11, Karlsbader Deklaration vom 26.4.1967, S. D 261, 263.

18 Vgl. Wettig, Ost-Berlin im Schatten, S. 268. Sowjetunion und DDR behaupteten, daß Bonn keinerlei Rechte in der Stadt besitze. Sie erklärten die seit 1949 geknüpften Verbindungen West-Ber-

lins zur Bundesrepublik kurzerhand zu neuen Ansprüchen Bonns und damit zu westdeutschen Anschlägen auf den Status quo. Die Bundesregierung attackiere die Selbständigkeit West-Berlins, und es eskaliere eine auf die Annexion gerichtete Politik, hieß es.

19 Vgl. Wettig, Ost-Berlin im Schatten, S. 268.

20 Vgl. DzD, 1966-1967, S. 2095 und 2271. 
Mitte Januar 1968 startete Moskau dann eine großangelegte, scharfe West-Berlin-Kampagne, der sich Ost-Berlin jeweils zwei Tage später anschloß. Mitte März 1968 durfte mit Billigung der Sowjets ${ }^{21}$ - die Führung der SED „Schritt um Schritt“ ihrem Anspruch durch Maßnahmen Druck verleihen. So nahm sie die Einrichtung eines Büros der radikal-konservativen Nationaldemokratischen Partei, die gerade bei Landtagswahlen spektakuläre Erfolge erzielte, zum Anlaß, eine „Anordnung zum Schutze der DDR und ihrer Bürger vor den Umtrieben der neonazistischen Kräfte der westdeutschen Bundesrepublik und der selbständigen politischen Einheit West-Berlin“ in Kraft zu setzen. Mitgliedern der NPD wurde die Einreise in die DDR und die Durchreise nach Berlin untersagt ${ }^{22}$.

Einen Monat später zielte der Angriff sogar auf die Minister und leitenden Beamten der Bundesregierung. Seit den fünfziger Jahren tagten die politischen Parteien, die Bundesregierung und auch das Kabinett sowie Ausschüsse des Bundestages in Berlin. Diese Tatsache, in den frühen fünfziger Jahren von der SED noch unter dem Aspekt des einen Deutschland begrüßt, erschien ihr jetzt als Provokation, da sie jegliche Verbindung zwischen Bonn und Berlin unterbrechen wollte. Pankow behauptete, diese Treffen seien ein Beweis dafür, daß die Bundesrepublik sich widerrechtlich West-Berlin aneignen wolle. Insgesamt wurden zwar bis Ende April nur 40 Personen an der Grenze zurückgewie$\operatorname{sen}^{23}$, am 26. April 1968 aber verweigerte die DDR dem Regierenden Bürgermeister Schütz die Durchreise. Ost-Berlin rechtfertigte die Maßnahme mit dem Hinweis, Schütz habe sich an der Grenze als Präsident des Bundesrates, den der Regierende damals turnusgemäß übernommen hatte, und nicht als West-Berliner Bürger ausgewiesen ${ }^{24}$. Trotz der Proteste der westlichen Alliierten gingen die Schikanen weiter. Am 11. Juni 1968 führte die Ost-Berliner Regierung auf den Transitstrecken den Paß- und Visazwang ein. Daneben wurden verschiedene Gebühren erhoben oder erhöht, so der Zwangsumtausch für die Einreise in die DDR von fünf auf zehn DM. Auf der Transitstrecke waren nunmehr pro Kopf zehn DM für Hin- und Rückweg zu zahlen.

Alle diese Ereignisse sorgten für große Aufregung. Die Bundesregierung befürchtete eine neue, eine dritte Berlin-Krise. Kiesinger begab sich nach Berlin, um mit den Vertretern der Drei Mächte zu konferieren. In einer Erklärung verurteilten die Schutzmächte das Vorgehen der DDR. Eine deutliche Sicherheitsgarantie gab einige Tage später der amerikanische Präsident. Er schrieb unter dem 16. Juni zum Tag der Deutschen Einheit an Kiesinger und versicherte, "that our support of free Berlin and the goal of a German people united in peace remains as firm as ever" ${ }^{25}$. Aber damit war es noch nicht getan.

\section{Kiesingers Propaganda während der kleinen Berlin-Krise}

Die Bundesregierung konnte die Erhebung von Gebühren, die Einführung von Visaund Paßzwang auf Anordnung von Pankow nicht einfach durchgehen lassen. Aber was

${ }^{21} \mathrm{Vgl}$. Wettig, Ost-Berlin im Schatten, S. $268 \mathrm{f}$.

22 DzD, 1968, S. 357.

23 Vgl. Wettig, Aktionsmuster, S. 336; die sowjetischen Proteste gegen sogenannte "neonazistische“ oder "faschistische" Aktionen in West-Berlin beriefen sich auf die im Potsdamer Abkommen beschlossenen Grundsätze, wonach jede nazistische Tätigkeit in Deutschland verboten sei. Moskau nutzte das propagandistisch geschickt aus: „Die sowjetischen Proteste implizieren die Vorstellung eines sowjetischen Interventionsrechtes hinsichtlich der inneren Angelegenheiten West-Berlins, wie es gegenwärtig nur die westlichen Besatzungsmächte mit ihrer Vetobefugnis besitzen.“ 24 Vgl. DzD, 1968, S. 614.

25 AdKASt, Kiesinger I - 226, D/IV.6, Johnson an Kiesinger am 16.6.1968. 
blieb Bonn anderes übrig, als sich erneut an seine Verbündeten zu wenden? Das tat Kiesinger am 21. Juni 1968. An diesem Freitag traf er sich mit Henry Cabot Lodge, dem Nachfolger McGhees als amerikanischem Botschafter in der Bundesrepublik. Er habe Cabot Lodge erklärt, teilte der Kanzler seinem Außenminister mit, er halte es für notwendig, daß die Vereinigten Staaten energisch auf die Rücknahme der neuen DDR-Maßnahmen drängten. Die Rechte der Siegermächte seien unmittelbar verletzt worden. Natürlich müsse Gesprächspartner der USA die Sowjetunion sein, ohne deren Einverständnis das Regime in Pankow keine Berlin betreffenden Entscheidungen fällen könne. Er sei überzeugt, daß mindestens weitere Schritte, die Berlin gefährden könnten, zu verhindern wären, wenn die Vereinigten Staaten jetzt eine feste Haltung einnähmen. Kiesinger unterließ es nicht, drohend hinzuzufügen: Falls weitere Aktionen folgten, würde dies unweigerlich zu einer schweren Vertrauenskrise im deutschen Volk gegenüber seinen Verbündeten, insbesondere gegenüber den USA, führen. Die Bundesregierung sei ihrerseits bereit, mit den ihr zur Verfügung stehenden Mitteln die Aktionen der Schutzmächte zu begleiten und zu unterstützen. Aber man dürfe sich nicht darüber täuschen, daß die deutschen Einwirkungsmöglichkeiten sehr beschränkt seien. Zufrieden über den Eindruck, den er auf Cabot Lodge gemacht zu haben glaubte, fügte er in seinem Schreiben an Brandt hinzu: „Der Botschafter zeigte sich sehr aufgeschlossen und versprach, von seiner Seite jede Unterstützung zu geben. Ich sagte ihm, daß ich sehr froh wäre, wenn Herr Rusk unsere Einladung, von Reykjavik nach Bonn zu kommen, annehmen könnte. Allein die Tatsache dieses Besuches würde eine große psychologische und politische Bedeutung haben. Ich bitte Sie daher, Herrn Rusk zu sagen, daß, wenn immer sein Gesundheitszustand diesen Besuch erlaube, ich ihm dafür sehr dankbar sein würde. "26

Die Bitte des Kanzlers wurde erhört. Rusk besuchte Bonn. Aber die Amerikaner konnten auch nicht viel mehr tun, als bei den Sowjets vorstellig zu werden. Für sie ging es um die Erhaltung von drei „Essentials“ in Berlin, die auf der Nato-Tagung in Oslo vom April 1961 für das Bündnis bindend erklärt worden waren: Es müsse die Aufrechterhaltung der alliierten Präsenz und Garnison in West-Berlin garantiert sein, hieß es da; der freie Zugang müsse gesichert und die Lebensfähigkeit und Freiheit des westlichen Teils erhalten bleiben ${ }^{27}$. Alle drei Bedingungen waren intakt geblieben, auch wenn die DDR ihre Macht- und Einflußmöglichkeiten demonstriert hatte. Daher reagierte der Westen lediglich mit Protesten.

Kiesinger schlug einen aggressiven Ton an. Die Ost-Berliner Führung hatte es dem Regierungschef leicht gemacht, sie propagandistisch in die Defensive zu drängen. Denn die harten Maßnahmen bestätigten des Kanzlers Behauptung, Pankow wolle im Grunde gar nicht mit Bonn verhandeln. In seiner Fernsehansprache zum Tag der deutschen Einheit sagte er, ein Vergleich zwischen der von der Bundesregierung und anderen westund osteuropäischen Regierungen angestrebten europäischen Friedensordnung und den Handlungen der SED beleuchte „den völlig erstarrten, unzeitgemäßen Charakter des Regimes in Pankow grell“. Die auf der Bereitschaft zur friedlichen Zusammenarbeit gründende Ostpolitik der Bundesregierung habe sich dagegen zum Ziel gesetzt, jede Möglichkeit gemeinsamer Arbeit für eine künftige europäische Friedensordnung zu nutzen, die das geteilte Europa und in ihm auch Deutschland wieder zusammenführten. „Das

26 AdKASt, Kiesinger I - 226, D/IV.6, A 001, Kiesinger an Brandt vom 21.6.1968, S. 2.

27 Vgl. Birrenbach (Meine Sondermissionen, S. 26), der behauptet, daß diese drei grundlegenden Bedingungen schon 1958, nach einer Besprechung zwischen General Lucius D. Clay und Marschall Georgij Schukow, vom State Department formuliert worden seien; siehe auch Brandt, Begegnungen, S. $18 \mathrm{f}$. 
erscheint den Verantwortlichen drüben für ihre Pläne bedrohlich. Deshalb wollen sie eine neue gefährliche Spannung erzeugen. Deshalb nehmen sie es in Kauf, vor aller Welt als Störenfriede der Entspannung aufzutreten." 28

Zugleich nutzte der Kanzler geschickt den propagandistischen Vorteil, den er aus dem einseitigen Vorgehen der DDR auf den Transitwegen zog, um die Haltung der Bundesregierung zum Sperrvertrag einzubeziehen und der Sowjetunion zu signalisieren, daß sich provozierte Störungen in und um Berlin auf andere Felder auswirken konnten. „Ein Instrument der Politik des Friedens soll der Atomsperrvertrag sein“, erklärte Kiesinger. „Um so wichtiger ist es, daß der Vertrag uns, die wir bereits früher auf atomare Waffen verzichtet haben, Schutz vor der möglichen Bedrohung und Erpressung durch atomare Mächte gewährt. Was am 11. Juni geschehen ist, ist aber gerade, daß die Sowjetunion einem nicht legitimierten, an Streit und Hader interessierten Regime ein Instrument der Drohung und Erpressung in die Hand gegeben hat." 29

Allerdings bekräftigte er die Gesprächsbereitschaft Bonns und bot der SED - trotz der Vorkommnisse - weiterhin die Verhandlungsgrundlage vom April 1967 an. Am 20. Juni 1968 machte Kiesinger vor dem Bundestag seinen Willen deutlich, an der Deutschlandpolitik festzuhalten. Man werde sich durch die Maßnahmen der DDR nicht zu falschen - vielleicht erwarteten - Reaktionen verleiten lassen. „Unser Verständigungsangebot schließt nach wie vor den anderen Teil Deutschlands ein “, rief er aus ${ }^{30}$. Propagandistisch konnte Kiesinger nicht nur nach außen in dieser Situation Punkte sammeln, sondern auch gegenüber beiden Fraktionen der Koalition.

\section{Moskaus Signale im Januar 1968}

Die Vorgänge um Berlin hatten Brandt beunruhigt - er unterbrach seinen Besuch in Belgrad, um nach Bonn zurückzukehren -, nicht aber seinen Glauben an die Notwendigkeit erschüttert, die Annäherungsbemühungen um den Osten fortzusetzen. Äußerungen von Vertretern der Sowjetunion zur Lage in Berlin bestärkten ihn in dieser Überzeugung. Anfang 1968 hatte Botschafter Zarapkin aus Moskau ein Aide-mémoire zur Berliner Situation nach Bonn mitgebracht. Das war insofern bemerkenswert, als sich hier zum ersten Mal die Sowjetunion an die Bundesregierung wandte, während bis dahin alle Proteste gegen die besonderen Bindungen zwischen der Bundesrepublik und Berlin an die Westmächte adressiert worden waren. Und ein Protestschreiben war auch dieses $\mathrm{Pa}$ pier in erster Linie. Aber Moskau mäßigte seinen Ton im Vergleich zu den früheren Noten. Es warnte lediglich vor deutschen Bestrebungen, die Fäden zwischen Bundesrepublik und Berlin noch enger zu verknüpfen. Andere Klagen, die früher immer wieder aufgetaucht waren, unterblieben dagegen. Die wirtschaftlichen Bindungen, die finanzielle Unterstützung durch den Bund, die Einbeziehung West-Berlins in Bundesgesetze und Handelsverträge der Bundesrepublik - selbst die Anwesenheit von Bundesbehörden in Berlin sowie die Zugehörigkeit Berliner Abgeordneter zum Bundestag ließ die Supermacht unerwähnt ${ }^{31}$.

Das Papier führte zu unterschiedlichen Einschätzungen der Motive Moskaus. So mutmaßte man im Auswärtigen Amt, die Sowjets wollten das ostdeutsche Regime besänftigen. Um Ulbrichts energischem, aber riskantem Vorstoß gegen West-Berlin den Stachel

${ }_{28}$ BPA, Rundfunk- und Fernsehansprache Kiesingers vom 17.6.1968, Anhang I, S. 2.

29 Ebenda, S. 2 f.

30 VdDB, 5. Wahlperiode, 180. Sitzung vom 20.6.1968, S. 9695.

$31 \mathrm{Vgl}$. Wagner, Das rätselhafte Papier Botschafter Zarapkins, Der Tagesspiegel, 24.1.1968. 
zu nehmen, wollte Moskau ein Teilergebnis anstreben, nämlich das bestehende Verhältnis zwischen Bundesrepublik und West-Berlin sollte eingefroren werden ${ }^{32}$. Eine zweite Interpretation besagte, daß die sowjetische Führung - völlig unabhängig von möglichen Rückwirkungen auf Ulbricht - eine engere Bindung zwischen der Bundesrepublik und Berlin verhindern wolle. Schließlich kam eine dritte Deutung zu dem Schluß, die Sowjetunion ziele langfristig auf eine weitergehende Veränderung des Status von Berlin. Zunächst wolle sie die Bundesregierung dazu verführen, der Sowjetunion besondere Rechte in West-Berlin und Westdeutschland einzuräumen. Später würde sie nach dieser These dann, mit Blick auf den angeblich zunehmenden Rechtsradikalismus in der Bundesrepublik, auf das Potsdamer Abkommen pochen und möglicherweise ein Besatzungsregime in ganz Berlin einzurichten versuchen ${ }^{33}$.

Brandt neigte zur ersten Einschätzung. Er hielt die Angelegenheit für so bedeutend, daß er das sowjetische Schreiben sogar vor seinen Mitarbeitern einige Tage verborgen hielt. Damit wollte er verhindern, daß der Text frühzeitig an die Öffentlichkeit gelangte. Lediglich seine Bemerkung im Januar 1968 zum Thema Berlin, er sehe keine Rechtfertigung für Meldungen über eine sich anbahnende Krise um Berlin, gab einen Hinweis darauf, daß sich der Außenminister im Besitz geheimer Informationen befand ${ }^{34}$. Als die DDR wenige Monate später den Paß- und Visa-Zwang einführte, sah alles aber wenig ermutigend aus. Auch wenn man Moskau die besten Absichten unterstellte, blieb die Aktion eine Provokation. An jenem Junitag besuchte Brandt gerade den jugoslawischen Staatspräsidenten. Tito ließ Brandt wissen, seine Kontakte deuteten darauf hin, daß die Sowjetunion keine aggressiven Absichten in Berlin verfolge ${ }^{35}$.

Das wollte er aber von den Sowjets selbst hören. Am 18. Juni 1968 traf Brandt daher mit Billigung des Bundeskanzlers in Ost-Berlin mit dem sowjetischen Botschafter in der DDR, Abrassimow, zusammen, jenem Diplomaten, der schon 1966 einige Male Gesprächspartner des damaligen Regierenden Bürgermeisters gewesen war. Der Außenminister wurde mit der sowjetischen Botschaftslimousine ohne Kontrolle wie selbstverständlich nach Ost-Berlin hinein- und wieder herausgebracht. Während des „begrenzt ertragreichen“ achtstündigen Gesprächs, wie Brandt im Rückblick schrieb, rief Breschnew persönlich an, um dem Außenminister versichern zu lassen, seine Seite wünsche keine Verschärfung der Situation, sondern Ruhe in und um Berlin ${ }^{36}$.

Neben dieser Versicherung brachte Brandt zwei Erkenntnisse nach Hause. Einmal zeigten sich die Sowjets aufgeschlossen gegenüber einer Regelung, Autobahngebühren auf der Transitstrecke pauschal zu erstatten. Zum anderen, und das war Brandt besonders wichtig, ergab die Unterhaltung zum Thema Gewaltverzicht ein erstes positives Anzeichen dafür, daß man in Moskau diesem Gegenstand ernstes Interesse entgegen-

$32 \mathrm{Vgl}$. Wettig (Ost-Berlin im Schatten, S. 268 f.), der darauf verweist, daß die Initiative von sowjetischer Seite ausgegangen sei. Die Massenmedien der DDR seien Moskau im Abstand von zwei Tagen gefolgt.

33 Vgl. Wagner, Das rätselhafte Papier.

${ }^{34}$ Vgl. Der Spiegel, 22.1.1968, S. 22.

35 Vgl. Brandt, Begegnungen, S. 234.

36 Brandt, Erinnerungen, S. 175. Moskau verfolgte also eine Doppelstrategie: Intern beruhigte man die Westmächte und sogar die Deutschen, nach außen führte man eine scharfe Kampagne gegen die bestehenden Rechte in Berlin. Von einer dritten Berlin-Krise zu sprechen, wie es Wettig in einigen Aufsätzen 1968 und 1969 getan hat, scheint allerdings im Rückblick übertrieben; vgl. Aktionsmuster, S. 339, und Die Berlin-Krise 1969, S. 685-697. Wettig ist auch später darauf nicht mehr zurückgekommen; siehe Die Sowjetunion, die DDR und die Deutschland-Frage, S. 55 ff. Man spricht daher allgemein von der „kleinen Berlin-Krise“. 
brachte ${ }^{37}$. Davon waren der Außenminister und auch sein Ministerium bis zu diesem Zeitpunkt nicht überzeugt gewesen.

\section{Kontakte zur Sowjetunion: Der Deal mit dem Olympiateam der DDR}

Das Bundeskanzleramt schätzte die sowjetische Bereitschaft zum Kompromiß eher gering ein. Kiesinger mahnte zur Vorsicht bei der Erwiderung sowjetischer Noten zum Gewaltverzicht, aber auch beim Gesprächsangebot über Berlin. Man solle darauf bedacht sein, der Gegenseite keine allzu großen Hoffnungen über Vorleistungen von deutscher Seite zu machen. Daher fiel die Antwort auf das sowjetische Berlinpapier vom Januar 1968 nüchtern aus. Die Bundesregierung versicherte lediglich ihrerseits, den Status Berlins nicht „unter Umgehung alliierter Beschlüsse“ verändern zu wollen. Nur dieser einzige Punkt deckte sich mit den sowjetischen Vorstellungen ${ }^{38}$. Kiesinger folgte hier seiner Idee einer Ostpolitik, wonach der mühselige Weg beschritten werden müsse, „der nicht verzichtet, der nicht preisgibt“ ${ }^{* 39}$.

Bei den Verhandlungen über einen Gewaltverzicht war man im ganzen Jahre 1967 nicht weitergekommen. Das Verhältnis zur Sowjetunion stagnierte eben rundum. Moskau schätzte nach wie vor die neue Ostpolitik als gefährlich ein. „Unsere Ostpolitik wird als störend und verdächtig empfunden“, zumal sie nicht frei sei "von Nadelstichen gegen die Sowjetunion “, berichtete Barzel Kiesinger über die Äußerung des sowjetischen Journalisten Lew Besyminski. Der Journalist habe in einer persönlichen Unterredung behauptet, es fehle eine Erklärung der Bonner Absichten gegenüber Moskau ${ }^{40}$. Dieser Hinweis sollte Kiesinger nicht mehr aus dem Kopf gehen. Auch er war der Meinung, daß sich ein Verhältnis mit Moskau nur dann entspannen und auf vertrauter Basis weiterentwickeln konnte, wenn sich zwischen Sowjets und Deutschen ein Kontaktfaden entspann. Und Kiesinger war der Meinung, daß sogar der Kanzler selbst die Person innerhalb der Regierung sein müsse, die in einen Dialog mit der Kremlführung eintreten sollte. Zwar gab es vertrauliche Gespräche. Sie fanden jetzt auch zwischen den Mitgliedern der Sowjetbotschaft in Bonn und der Bundesregierung häufiger statt. Aber nicht nur der Fraktionsvorsitzende der CDU/CSU, sondern auch die SPD suchte solche Kontakte. Journalisten beobachteten, wie, anders als in den Jahren zuvor, sowjetische Botschaftsangehörige im Auswärtigen Amt ein- und ausgingen ${ }^{41}$. Solchen Treffen stand der Kanzler, wenn er davon hörte, mißtrauisch gegenüber. Sein Ziel war, das Verhältnis zwischen Bonn und Moskau vom Auswärtigen Amt auf das Kanzleramt zu übertragen.

Auf einem Empfang des Auswärtigen Amtes im Herbst 1967 testeten die Sowjets die Bereitschaft der Westdeutschen, auf die DDR zuzugehen. Gegenüber dem Ministerialdirektor im Ministerium für gesamtdeutsche Fragen, Kreutzer, regte ein sowjetischer Botschaftsrat an, ob man nicht gemeinsam „einen Akzent setzen“ könne, der den guten Willen beider Seiten unterstreiche. Die Sowjets dachten daran, die DDR-Sportmannschaft mit einem Flugzeug der Interflug über bundesdeutsches Territorium zu den Olympischen Winterspielen nach Grenoble fliegen zu lassen. Wehner fand den Vorschlag an-

\footnotetext{
37 Vgl. Brandt, Erinnerungen, S. 175.

$38 \mathrm{DzD}$, Mitteilung der Bundesregierung an die Regierung der UdSSR zur Berlin-Frage vom 1.3.1968, S. 287.

39 Buchstab, Geheimdiplomatie zwischen zwei bequemen Lösungen, CDU/CSU-Bundestagsfraktion am 5.9.1967, S. 901.

40 AdKASt, Kiesinger I - 226, D/IV.6, A 002, Barzel an Kiesinger vom 13.9.1967, S. 2.

41 Vgl. Dreher, Gespräch mit dem Verfasser, 5.7.1988.
} 
nehmbar. Zusammen mit Kreutzer suchte er nach einer angemessenen Gegenleistung. Man verfiel auf den Gedanken, daß die DDR Sonderzüge für das Deutsche Turn- und Sportfest, das im Mai 1968 in Berlin stattfinden sollte, ohne die damals üblichen stundenlangen Grenzkontrollen passieren lassen könnte. Mit dieser Idee ging Wehner zum Kanzler. Kiesinger sei sofort dafür gewesen, berichtet Kreutzer ${ }^{42}$. Das Arrangement mit der DDR gelang. Die Olympiamannschaft der DDR flog direkt von Ost-Berlin nach Grenoble über bundesdeutsches Hoheitsgebiet, und im Mai 1968 kamen mehr als hunderttausend Menschen nach Berlin, ohne durch zermürbende Kontrollen aufgehalten worden zu sein.

Aber eine solche beiderseitige Geste blieb die Ausnahme. Der Kreml hielt an den strengen Auflagen für eine erfolgreiche Fortsetzung der Ostpolitik der Großen Koalition fest. Das galt insbesondere für die weiteren Gewaltverzichtsverhandlungen. Die Sowjetunion hatte im Januar 1968 ein Aide-mémoire nach Bonn geschickt und darin noch einmal festgehalten, der Austausch von Gewaltverzichtserklärungen setze voraus, daß die Bundesregierung „ihre Haltung zu solchen Fragen der europäischen Sicherheit definiert, wie zur Anerkennung der bestehenden Grenzen in Europa durch die Bundesrepublik, zum Verzicht auf die Anmaßung, im Namen aller Deutschen zu sprechen, zur Einstellung aller Anstrengungen, Zutritt zu Kernwaffen zu erlangen, zum Verzicht auf die rechtswidrigen Anschläge auf West-Berlin sowie zur Anerkennung der Ungültigkeit des Münchner Abkommens von Anfang an"43.

Man kam also kaum voran im Verhältnis zur Sowjetunion. Wie sollte sich die Bundesregierung weiter verhalten? Sollte sie auf den bestehenden Positionen in der Ostpolitik beharren oder von ihnen abrücken? Und wenn, von welchen? Der Kanzler und sein Außenminister fanden unterschiedliche Antworten auf diese Frage.

\section{Kiesinger verhindert die Unterzeichnung des Atomsperrvertrages durch die Bundesrepublik}

Trotz der im Kanzleramt mit Skepsis bewerteten sowjetischen Note vom Januar 1968 über den Gewaltverzicht setzte Brandt jetzt alles daran, einen Antwortentwurf erarbeiten zu lassen. Er sollte Anhaltspunkte enthalten, die die Sowjets ermutigten, den Dialog weiter voranzutreiben. Nachdem das Kanzleramt bereits auf das sowjetische Berlinpapier vom Juni 1967 ohne Enthusiasmus geantwortet hatte, durfte jetzt das Auswärtige Amt die Note zum Gewaltverzicht formulieren. Am 9. April 1968 übergab die Bundesregierung ihre Antwort an den sowjetischen Botschafter.

Die Schwierigkeit Brandts bestand darin, das Angebot des Gewaltverzichts für Moskau interessant zu gestalten, ohne von der Linie der Bundesregierung abzugehen. Der Kanzler und seine Partei wollten ein solches Abkommen nur für den Fall schließen, daß die Sowjets von jenen Forderungen an die Bundesrepublik abrückten, die sie gerade wiederholt und deutlich herausgestellt hatten. Daher blieb dem Auswärtigen Amt bei der Formulierung der Antwort nicht viel mehr übrig, als allgemein freundliche Worte zu wählen, die den gemeinsamen Willen zum Gewaltverzicht herausstrichen. Es sei der Bun-

\footnotetext{
42 Kreutzer, Gespräch mit dem Verfasser, 22.8.1988. Außerdem wurde damals Verkehrsminister Leber eingeschaltet.

${ }^{43}$ DzD, Aide-mémoire vom 29.1.1968, S. 123.
} 
desregierung eine Befriedigung, feststellen zu können, lautete demnach der Anfang der Antwortnote, daß die Regierung der UdSSR eine Verbesserung ihrer Beziehungen zur Bundesrepublik Deutschland anstrebe. Dann folgte der entscheidende, der einzig konkrete Vorschlag: die deutsche Zustimmung zum Nichtverbreitungsvertrag wurde in Aussicht gestellt. Hier ging Brandt allerdings wieder einen Schritt weiter, als es dem Kanzler lieb war, wenn es in der Note hieß: „Die Regierung der Bundesrepublik Deutschland sieht wie die Regierung der UdSSR in einem weltweit annehmbaren Vertrag über die Nichtverbreitung von Kernwaffen auch ein Mittel, in Europa den Frieden zu festigen und weitere Schritte der Entspannung zu erleichtern, insbesondere wenn damit ein Ausschluß von Druck, Drohung und Erpressung verbunden wäre. Die Regierung der Bundesrepublik Deutschland hofft, daß ein solcher Vertrag zustande kommen wird und alle Partner an dem zur Diskussion stehenden Austausch von Gewaltverzichtserklärungen ihm beitreten werden. “" ${ }^{44}$ Tatsächlich stimmte der Kanzler dieser formulierten Haltung nicht mehr zu.

\section{Der Erfolg des Bundeskanzlers: Die verstärkte Hinwendung der USA zu den europäischen Problemen ab dem Frühjabr 1967}

Kiesinger hatte mittlerweile seine Entscheidung getroffen: Er wollte die deutsche $\mathrm{Zu}$ stimmung zum Sperrvertrag hinauszögern, wenn möglich ganz verweigern. Aber er war sich bewußt, daß er den Vertrag nicht ablehnen konnte, falls die USA sämtliche deutsche Bedenken ausräumen würden, auf die Bonn unermüdlich aufmerksam machte. Die Bundesregierung hatte immer auf den positiven Charakter des Vertrages hingewiesen und konnte sich daher ihm nicht plötzlich entziehen. Der Kanzler bemühte sich dennoch, Zeit zu gewinnen; er hoffte auf eine internationale Konstellation, die vielleicht den Sperrvertrag verhindern würde. Es war denkbar, daß die beiden Supermächte keine Einigkeit in den strittigen Fragen erzielten. Dann war die Bundesregierung, so hoffte Kiesinger, der lachende Dritte.

Es war dem Kanzler gelungen, durch das Wort eines „atomaren Komplizentums“ die Aufmerksamkeit der verbündeten Schutzmacht wieder stärker auf die Bundesrepublik zu lenken; Washington nahm seither Bonns Einwände ernster als zuvor. Kiesinger betrachtete seine Kritik an den USA als „reinigendes Gewitter“ im spannungsreichen Verhältnis der beiden Verbündeten. Seit jenem Krach Anfang 1967 habe keine amerikanische Regierung bei ihm mehr darauf gedrängt, daß dieser Vertrag von den Deutschen unterzeichnet werden müsse, meinte Kiesinger später ${ }^{45}$. Tatsächlich hinterließ die Äußerung des Kanzlers einen tiefen Eindruck bei der amerikanischen Administration. Die Beziehungen seien auf dem "Tiefpunkt“ angelangt, telegrafierte Botschafter McGhee an Außenminister Rusk kurz nach der Äußerung Kiesingers. Die größte Belastung des deutsch-amerikanischen Verhältnisses sei allerdings der Sturz Erhards gewesen, fügte er hinzu. In Bonn nehme man an, die Vereinigten Staaten seien daran schuld gewesen ${ }^{46}$.

Wirklich hatte Erhard im Herbst 1966 Washington in der Hoffnung besucht, die USA würden der Bundesrepublik angesichts einer Haushaltslücke von vier Milliarden DM einen Aufschub bei der vertraglichen Verpflichtung zu Waffenkäufen in den Staaten gewähren. Als der Präsident diese Bitte abschlug, trug dies zu einem weiteren Anse-

${ }^{44} \mathrm{DzD}$, Aide-mémoire an die UdSSR vom 9.4.1968, S. 573.

45 AdKASt, Kiesinger I - 226, F/3., A 322, Gespräch mit Löwe, 31.1.1978, S. 10.

46 McGhee, Botschafter in Deutschland, S. 306. Das war eine Meinung, die McGhee teilte und auch nach eigenen Angaben Präsident Johnson gegenüber erläutert hatte. 
hensverlust des Kanzlers in Bonn bei. Wenig später brach die Regierungskoalition von CDU/CSU und FDP auseinander. Obwohl Präsident Johnson jede Mitschuld am Schicksal Erhards ablehnte, ließ der Staatssekretär im Auswärtigen Amt, Carstens, seine amerikanischen Kollegen bei jeder Gelegenheit wissen, daß man in Bonn eine andere Überzeugung habe ${ }^{47}$. Tatsächlich schien sich die Haltung in den USA jetzt gegenüber der Bundesrepublik zu verbessern. Washington kam Bonn spürbar entgegen. Das leidige Thema der Truppenausgleichszahlungen wurde im Frühjahr 1967 zur Zufriedenheit der Deutschen geklärt, nachdem die US-Regierung den früheren Hochkommissar John McCloy entsandt hatte. McCloy, ein zuverlässiger Fürsprecher deutscher Interessen, brachte die Verhandlungen zu einem schnellen Ende ${ }^{48}$. Künftig brauchte die Bundesregierung ihre Verpflichtungen nicht mehr ausschließlich in Waffenkäufen abzugelten. Damit war ein Streitpunkt weggeräumt, der das Verhältnis beider Staaten ständig belastet hatte. Auch der Gesandte an der Washingtoner Botschaft Lilienfeld registrierte die plötzliche Besserung im deutsch-amerikanischen Verhältnis. Er wolle den Bundeskanzler über Dinge unterrichten, die in den offiziellen Berichten nicht zum Ausdruck kämen, schrieb Lilienfeld am 6. März 1967. Kiesinger habe bei der amerikanischen Regierung und in der Öffentlichkeit großes Ansehen gewonnen. Das zeige sich daran, daß die Regierung der USA nach monatelangem Hin und Her eine deutliche „Wendung auf Europa und auf uns vorgenommen habe "49. Man dürfe allerdings nicht vergessen, daß manche der Entscheidungen Johnsons vom Herbst 1966 aus Enttäuschung über die Schwäche der vorherigen Bundesregierung und der aus ihr resultierenden Stagnation in Europa verursacht worden seien, milderte er seine Kritik an der US-Administration. Für die Zukunft empfahl Lilienfeld eine kompromißbereite, aber standfeste Haltung in bezug auf den Sperrvertrag. Man solle sich auf die Hauptpunkte konzentrieren, bei denen die deutschen Wünsche als durchaus gerechtfertigt anerkannt würden. Das gelte insbesondere für die Kontrollfrage.

Der Kontrollartikel war bei den Parteien in zweifacher Weise auf Widerstand gestoßen. Einmal befürchteten insbesondere die Experten in der Union, die im Vertrag vorgesehene Internationale Kontrollbehörde mit Sitz in Wien werde den Sowjets Zugang zu Forschungsstätten in der Bundesrepublik ermöglichen. Das erhöhe die Gefahr, ganz legal von Moskau ausspioniert zu werden. Außerdem - darauf wiesen die Gegner des Vertrages hin - sei die Bundesrepublik durch die Mitgliedschaft in der europäischen Atombehörde EURATOM bereits seit 1958 zu Kontrollen verpflichtet, andere Kontrollmechanismen seien daher überflüssig. Bedenken hegte die Bundesregierung zum anderen, weil der Vertrag die Zielsetzung eben dieser europäischen Atomorganisation in Frage stellte. Die Behörde war Teil des Vertrages von Rom, der 1957 unterzeichnet worden war, um einen wirtschaftlichen Markt gleichberechtigter Partner zu schaffen. Mit dem Sperrvertrag wurde nunmehr ein Element der Diskriminierung eingeführt: Die Staaten unterschieden sich künftig in Kernwaffenstaaten, die keiner Kontrolle unterlagen, und Länder, die keine Kernwaffen besitzen durften, aber sich einer ständigen Überwachung

47 Vgl. Carstens, Gespräch mit dem Verfasser, 29.11.1989.

48 Vgl. ebenda; McCloy habe die Verhandlungen in ein ruhiges Fahrwasser geleitet, beschreibt Carstens den Verdienst des Amerikaners. Carstens nahm als Staatssekretär für die deutsche Seite an den Verhandlungen teil, bis er vom Staatssekretär des Auswärtigen Amtes, Duckwitz, abgelöst wurde.

49 AdKASt, Kiesinger I - 226, D/IV.6, A 006, Lilienfeld an Kiesinger vom 6.3.1967. „Auch wissen wir nie recht, ob Ihnen die Telegramme vorgelegt werden, die wir für wichtig halten", heißt es da mißtrauisch gegenüber der sozialdemokratischen Führung im Auswärtigen Amt. 
unterziehen mußten. Dieses Element der Diskriminierung konnte langfristig dazu führen, daß Länder mit Atomwaffenbesitz wie Frankreich und Großbritannien ungehindert neue Produktionsmethoden entwickelten und billiger produzierten. Damit drohten sie das im Römischen Vertrag vorgesehene Prinzip des gleichen Wettbewerbs außer Kraft zu setzen.

Die Bundesregierung wandte sich also gegen folgende Punkte des Sperrvertrages: Erstens stellte sie sich gegen Kontrollen durch die Wiener Kontrollbehörde. Wenn überhaupt Kontrollen durchgeführt werden sollten, dann nur durch EURATOM. Zweitens sollten - aus Schutz vor Spionage - nicht die Anlagen selbst geprüft werden, sondern nur das Uran einer Kontrolle unterliegen. Lediglich Quantität und Anreicherung des Materials sollten überprüfbar sein ${ }^{50}$.

Lilienfeld meinte in einem Brief vom 6. März 1967, die Regierung der Vereinigten Staaten vermute inzwischen selbst, den Sowjets in diesem Punkt zu sehr entgegengekommen zu sein. "Wie wir [die Botschaft] berichtet haben, ist man hier offenbar etwas besorgt, in der Kontrollfrage zu weit gegangen zu sein." Aber er riet dem Kanzler auch dazu, insgesamt vorsichtig zu operieren. „Manche der anderen Punkte (allgemeine nukleare Abrüstung, nukleare Sicherheitsgarantien und anderes mehr) könnte man auch anderen Mächten überlassen, damit nicht alle ,Bedenken" nur von uns kommen. "51 Lilienfeld lobte die seiner Meinung nach recht geschickte Äußerung des Außenministers, der betont habe, daß die Deutschen die Zielsetzung des Vertrages begrüßten. Diese Art sei geeignet, sich vom „Odium des Störenfriedes“ zu befreien.

\section{Kiesingers Position zum Atomsperrvertrag seit März/April 1967}

Aber der Bundeskanzler stimmte Lilienfelds Auffassung nicht zu. Die Bedenken gegen den Sperrvertrag hingen mit seiner ostpolitischen Konzeption zusammen. Er befürchtete, daß der Kernwaffensperrvertrag die von ihm angestrebte Auflösung der Blocksysteme und damit die Vereinigung der beiden deutschen Staaten verhindern konnte. In einer Welt, in der sich die Supermächte die qualitativ am höchsten entwickelte Waffe vorbehielten, bestehe die Gefahr, daß sich die existierenden Strukturen dauerhaft verfestigten, machte Kiesinger intern seine Meinung deutlich. Denn es entstünden zwei Arten von Staaten: souveräne und nur scheinbar souveräne. Die Supermächte, vor allem die Sowjetunion, hätten als Atommächte die Möglichkeit, jeden anderen Staat zu beherrschen. Zumindest könne Moskau dann ganz Europa bedrohen und vor allem auch dominieren. Unter diesen Bedingungen würden die westeuropäischen Staaten zu Recht lieber an den bestehenden Bündnissen und der Teilung Europas festhalten wollen, anstatt sich in einem "geeinten", aber nur schwach geschützten Europa der Sowjetunion auszuliefern ${ }^{52}$.

Die Deutschen machten aus ihrer Skepsis keinen Hehl. Ihr Verhandlungsleiter Schnippenkötter bestätigte dem amerikanischen Botschafter McGhee, daß Kiesinger sich von dieser Argumentation leiten ließ. Im wesentlichen habe die Auffassung des Kanzlers ihre Wurzel in seiner Weigerung, „künftige deutsche Generationen“ an einen Vertrag zu binden, dessen Konsequenzen nicht gänzlich abzusehen seien. Es sei völlig unklar, was pas-

50 Vgl. EA 22 (1967), Folge 24, Antwort der Kommission der Europäischen Gemeinschaft auf eine mündliche Anfrage des Politischen Ausschusses des Europäischen Parlaments betreffend die Auswirkungen eines Kernwaffen-Sperrvertrages auf die Gemeinschaft, vorgetragen vom Kommissionsmitglied Edoardo Martino am 18.10.1967, S. D 579.

51 AdKASt, Kiesinger I - 226, D/IV.6, A 006, Lilienfeld an Kiesinger vom 6.3.1967.

52 Hildebrand, Erhard, S. 311. 
sieren werde, wenn es unter diesen Umständen im Jahre 1969 - der Nordatlantikpakt war für die Dauer von 20 Jahren abgeschlossen worden - zu einer Auflösung der Nato komme. Deutschland werde dann, machte er die Befürchtungen des Kanzlers deutlich, der Willkür der Sowjets schutzlos ausgeliefert sein ${ }^{53}$.

Hier lag der Kern des Dilemmas von Kiesingers Ostpolitik: Während die Zustimmung zum Sperrvertrag die einzige Möglichkeit darstellte, das Verhältnis zu den Sowjets zu verbessern und ihr Vertrauen zu gewinnen, glaubte der Kanzler, der Vertrag werde ein geeintes Europa und damit auch die Einheit Deutschlands verhindern. Er erwog daher frühzeitig die Möglichkeit, dem Vertrag eine Fristklausel beizufügen. Man könne zustimmen, äußerte Kiesinger Brandt gegenüber, falls das Vertragswerk nur über eine Laufzeit von fünf oder zehn Jahren gültig sei. Diesen Vorschlag sollte sein Außenminister den Amerikanern unterbreiten. Als Rusk am 10. April 1967 Bonn besuchte, bestand Brandt im Namen seiner Regierung darauf, daß der Vertrag nur über einen Zeitraum von fünf Jahren laufen sollte. Ohne Kündigungsmöglichkeit nach einer bestimmten Zeit, warnte Brandt, werde er sich mit seiner Zustimmung in der internen politischen Auseinandersetzung kaum durchsetzen können ${ }^{54}$.

Aber die USA waren nicht bereit, eine Fristenklausel in den Vertrag über die Nichtweitergabe von Atomwaffen einzubauen. Rusk warnte wiederum Brandt, es könne sein, daß einige Mitglieder, die noch an den Nato-Vertrag gebunden seien, eine Rücktrittsklausel des Atomsperrvertrages in Anspruch nähmen, um aus dem westlichen Bündnis auszutreten. Der Amerikaner dachte vor allem an Frankreich ${ }^{55}$. Doch der Bundeskanzler ließ sich nicht von solchen Argumenten beeindrucken. Am 18. April tagte der Bundesverteidigungsrat, und man sprach sich, unter seinem Vorsitz, mehrheitlich für eine zeitliche Begrenzung des Vertrages aus. Erst wenn diese Regelung in den Vertrag aufgenommen worden sei, könne man an eine Unterzeichnung denken, hieß es.

Das Auswärtige Amt schien allerdings zum selben Zeitpunkt die Bedeutung, die Kiesinger und der Rat einer Vertragsbefristung beimaßen, noch nicht entsprechend berücksichtigt zu haben. Dort war man darauf eingestellt, daß die Bundesregierung irgendwann, eher früher als später, den Vertrag unterzeichnen werde. Man hielt es für unklug, den Beitritt zum Atomsperrvertrag zu verweigern. Die Verfolgung des deutschlandpolitischen Ziels der Wiedervereinigung werde dadurch gefährdet, argumentierten die Beamten intern. Denn das Streben nach atomarer Bewaffnung wurde den Westdeutschen als kriegerische Haltung ausgelegt, als Revanchismus und Militarismus, wie die sowjetische Propaganda anklagend behauptete. Eine Verweigerung des Beitritts schien diesen Vorwurf der Sowjets zu bestätigen ${ }^{56}$. Vielleicht aus diesem Grund hatte das Auswärtige Amt in der Vorbereitungsmappe für die Gespräche des Kanzlers mit dem amerikanischen Präsidenten am 24. und 26. April in Bonn die Befristung gar nicht berücksichtigt. Der Kanzler warf daher noch am Tag der Ankunft Johnsons Brandt vor: In der Gesprächsmappe für seine Gespräche mit Präsident Johnson werde unter den Problemen, die das geplante NV-Abkommen für die Bundesregierung aufwerfe, die Frage der Befristung gar nicht

53 McGhee, Botschafter in Deutschland, S. 328.

${ }^{54} \mathrm{Vgl}$. ebenda, S. $326 \mathrm{f}$.

55 Vgl. ebenda, S. 326. Der Amerikaner rechnete außerdem vor, daß bei den internen Gesprächen inzwischen 25 Änderungen aufgrund deutscher Einwände vorgenommen worden seien. Brandt versprach daher, den Vertrag nunmehr dem Bundestag vorzulegen. Aber er machte auch klar, dort werde keine Entscheidung fallen, sondern es handele sich um eine allgemeine Diskussion.

$56 \mathrm{Vgl}$. Diehl, Gespräch mit dem Verfasser, 29.11.1989. Wenn die deutsche Frage nicht gewesen wäre, dann hätte man den Beitritt eventuell ablehnen können, bestätigte Diehl diese Einschätzung. 
erwähnt. Kiesinger betonte: „Ich messe jedoch gerade dieser größte Bedeutung bei. Ich neige dazu, den Amerikanern unsere Beteiligung an dem NV-Abkommen in Aussicht zu stellen, wenn das bisher in den deutsch-amerikanischen Konsultationen Erreichte bewahrt und der Vertrag zunächst auf eine Dauer von 10 Jahren befristet wird. “57 Nach Ablauf dieser Frist sollten Wirksamkeit und Erfüllung aller proklamierten Vertragsziele überprüft werden. Er lege auf die Frage der Befristung um so größeren Wert, als er von Beschlüssen der CSU erfahren habe, die auf eine Ablehnung des Vertrages drängten. Solche Schwierigkeiten könnten durch eine Befristung wohl überwunden werden.

Doch die Gespräche beim ersten Zusammentreffen zwischen dem US-Präsidenten und dem Bundeskanzler im April 1967 in Bonn ergaben in der Sache keinen Fortschritt. Johnson beklagte sich über Kiesingers Bemerkung eines ,atomaren Komplizentums" der Supermächte. Ihm war der Zorn noch anzumerken, den er über das Wort empfunden hatte. Aber der Kanzler, der vor dem schauspielerischen Talent des Präsidenten gewarnt worden war ${ }^{58}$, wiegelte ab. Später erzählte er, er habe Johnson noch einmal gesagt: „Wir haben ja überhaupt nichts mehr gemeinsam, wir reden nicht mehr miteinander. Wir haben keine Kontakte miteinander." Daraufhin habe Johnson widersprochen: Jeden Tag drängten so viele Deutsche ins Weiße Haus hinein, die hätten sich da festgesetzt, die lebten da. Kiesinger aber habe geantwortet: „Herr Präsident, schmeißen Sie alle raus. Auf den Kontakt zwischen uns beiden kommt es an. " 59

Bei ihrer Abreise hatten die Amerikaner die Deutschen darum gebeten, einen detaillierten Vorschlag zu unterbreiten, wie denn der Vertrag am Ende aussehen solle. Das brauchte erst einmal Zeit. Außerdem wußte Lilienfeld zwei Wochen später, am 8. Mai, die gute Neuigkeit zu berichten, daß der amerikanische Enthusiasmus über das Vertragswerk offenbar verflogen und einer nüchternen Betrachtung gewichen sei. In persönlichen Gesprächen mit dem stellvertretenden Außenminister George Ball und Sicherheitsberater Rostow klinge eine gewisse Skepsis an „hinsichtlich des Zustandekommens des Vertrages"60. Hinzu kam, daß die Haltung anderer nicht-nuklearer Staaten, vor allem diejenige Indiens, des wichtigen Sprechers der unabhängigen, „non-aligned“-Welt, Kiesinger bestärkte, jetzt einfach abzuwarten, nichts zu versprechen, keine Verpflichtung einzugehen. Der stellvertretende Premierminister Morarji Ranchhodji Desai habe ihm klar und deutlich gesagt, daß Indien diesen Vertrag nicht unterzeichnen werde, berichtete der Kanzler im Oktober 196761. Andererseits machte er sich zugleich keine Illusionen darüber, daß sich die Bundesrepublik einer Vertragsunterzeichnung auf Dauer nicht verweigern konnte. Dafür sprach nicht zuletzt ein innenpolitischer Aspekt: In Wirklichkeit gäbe es für den Atomsperrvertrag im Bundestag eine Mehrheit aus SPD und FDP, räumte der Kanzler im Gespräch vertraulich ein.

Dennoch gab Kiesinger seine Hoffnung nicht auf, daß die Umstände es der Bundesregierung erlaubten, vielleicht doch noch um eine Vertragsunterzeichnung herumzu-

57 AdKASt, Kiesinger I - 226, D/IV.6, A 001, Kiesinger an Brandt vom 24.4.1967, S. 1 f.

$58 \mathrm{Vgl}$. Weber, Gespräch mit dem Verfasser, 26.10.1989.

59 AdKASt, Kiesinger I - 226, F/3., A 322, Gespräch mit Löwe, 31.1.1978, S. 38. Johnson habe getobt, meinte Kiesinger.

60 AdKASt, Kiesinger I - 226, D/IV.6, A 006, Lilienfeld an Kiesinger vom 8.5.1967. Und in dem handschriftlichen Nachgang hieß es wörtlich weiter: „Auch scheint es mir, als ob Präsident J. ein wenig die Lust an der ganzen Sache verloren hat. Nach Präzisierung Ihrer Gedanken zur zeitlichen Befristung sollten wir daher dann zunächst eine abwartende Haltung einnehmen.“

61 Vgl. AdKASt, Kiesinger I - 226, D/II.1, A 008, Gespräch mit Wirsing, 5.10.1967, S. 7; dort auch die folgenden Bemerkungen. 
kommen. Noch im Oktober 1967 wollte er nicht ausschließen, daß der Vertrag noch scheitern könne. Denn auf den deutschen Verhandlungsführer, den Diplomaten Schnippenkötter, könne er sich ganz verlassen: „Er arbeitet ganz in meine Richtung, nämlich alles daranzusetzen, daß die Frage so lange weitergeschoben wird, bis sie schließlich doch versandet."

\section{Frübjabr 1968: Die Position Kiesingers wird unbaltbarer}

Aber der Verlauf der Verhandlungen machte es immer schwieriger, die Bonner Zustimmung zum Sperrvertrag hinauszuzögern. Im August 1967 hatten die Vereinigten Staaten und die Sowjetunion den ersten Entwurf eines Vertrages über die Nichtverbreitung von Kernwaffen in Genf vorgelegt, in dem der Kontrollartikel noch ausgelassen worden war. In der revidierten Fassung vom 18. Januar 1968 war der Wortlaut dieses Artikels allerdings enthalten. Der Kontrollartikel berücksichtigte dabei weitgehend die Grundsätze einer von den fünf EURATOM-Staaten (Bundesrepublik, Italien und die Benelux-Länder) eingesetzten Kommission. Die Kontrollen, so hatte die Kommission gefordert, sollten sich auf den Fluß des spaltbaren Materials, also die Verschickung bestimmter Mengen von Uran oder anderer Stoffe, beschränken. Kontrolleure sollten die verarbeitenden Anlagen, die Kernstabproduktionsfabriken und Reaktoren nicht inspizieren dürfen. Außerdem schlug man ein Abkommen zwischen EURATOM und der Internationalen Atomenergieorganisation (IAEA) vor, in dem die Verifizierung der EURATOM-Kontrollen durch die IAEA festgelegt werden sollte. Die Wiener Kontrollbehörde würde also nur die Richtigkeit der Kontrollen von EURATOM bestätigen und keine eigenen Untersuchungen durchführen. Darüber hinaus drang die Kommission darauf, daß die Brennstoffversorgung der Europäischen Gemeinschaft gesichert werden müsse.

In der Fassung vom 18. Januar hatten die beiden Supermächte im Artikel III tatsächlich auf die Kontrolle von Kernanlagen verzichtet ${ }^{62}$. Außerdem war ein Abkommen zwischen EURATOM und IAEA vorgesehen, das eine Abschlußfrist fixierte. Insgesamt waren damit wesentliche Vorbedingungen der Europäer erfüllt worden ${ }^{63}$, und deshalb geriet Kiesinger mit seinem Versuch, die Zustimmung der Bundesregierung zu verzögern, mehr und mehr in eine aussichtslos erscheinende Lage. Im Februar 1968 fuhr Barzel nach New York und traf sich dort heimlich mit Rostow. Er wollte ausloten, welche Folgen eine deutsche Weigerung, den Vertrag zu unterzeichnen, vermutlich haben könnte. In einem Brief vom 15. Februar hatte Barzel gegenüber Kiesinger erklärt, daß sich nach seinem Eindruck der Widerstand in der Bundestagsfraktion der CDU/CSU versteife ${ }^{64}$. Auch Barzel selbst beurteilte das Unternehmen zunehmend skeptisch. Während seines Treffens mit Rostow - den er im Brief an Kiesinger geheimnisvoll mit „R.“ bezeichnet ${ }^{65}$ -

$62 \mathrm{Vgl}$. Bechtoldt, Atomsperrvertrag, S. 258.

${ }^{63}$ Vgl. EA 23 (1968), Folge 9, Vortrag des Kommissionsmitglieds Martino vor dem Europäischen Parlament, S. D. 223 f. Die Kommission kam am 12.3.1968 zu dem Schluß: „Der neue Text bestätigt eine langsame, aber ständige Entwicklung hin zu den westlichen Positionen." Bechtoldt (Atomsperrvertrag, S. 258) weist zu Recht darauf hin, daß der Vertrag einer Gegenleistung der Kernwaffenstaaten entbehre. Zwar werde von den Nichtmitgliedern des Atomklubs ein freiwilliger Verzicht gefordert, aber die Nuklearmächte selbst seien nicht bereit, auf militärische Mittel zu verzichten.

${ }^{64} \mathrm{Vgl}$. AdKASt, Kiesinger I - 226, D/IV.6, A 002, Barzel an Kiesinger vom 15.2.1968: „Mir gehen auch Informationen zu, nach denen bei einigen Freien Demokraten insoweit erhebliche Bedenken anwachsen."

65 Vgl. Barzel, Gespräch mit dem Verfasser, 10.6.1988, in dem er die Identität „R's“ enthüllte. 
legte der Deutsche seine grundlegenden Bedenken gegen den Vertrag dar. Erst durch dieses Gespräch hätten die Amerikaner verstanden, weshalb die Deutschen dem NVVertrag so ablehnend gegenüberstünden, brüstete sich Barzel später. Durch seinen Bericht erfuhr der Kanzler allerdings, wie weit die Verhandlungen im Frühjahr 1968 bereits gediehen waren. Barzel schrieb unter anderem:

"Nachdem ich nochmals zum NV-Vertrag erhebliche Bedenken konkretisiert hatte, wurde mir folgender ,Fahrplan' mitgeteilt: 15. März Bericht der Genfer-Kommission an UNO und Regierungen, Debatte der UNO im April, Unterzeichnungen ab Mai: Das Interesse, diesen Plan auch einzuhalten, schien mir sehr stark. Basis des Vertrages sei: Nur was im Vertrag ausdrücklich abgemacht werde, sei verbindlich. Über friedliche Forschung und Entwicklung, McNamara-Komitee, Zwei-Schlüssel-System u.a. sei nichts abgemacht. Theoretisch erlaube der Vertragstext eine MLF. Ich äußerte erneut Zweifel.“66

Besonders wichtig erschien Barzel die Nachricht, es bestehe offenbar in den USA der Eindruck, des Kanzlers Einwände beträfen „vor allem die Dauer des Vertrages und das EURATOM-Problem “. Am Schluß faßte der CDU-Fraktionsführer seinen Eindruck zusammen und empfahl - wie die Dinge lägen - einen dringenden Brief „mit den offenen Fragen nach hier ebenso wie das Einwirken auf Genf in Richtung ,Diskussionsgrundlage'. Weiter müßte wohl erstrebt werden, daß EURATOM ,mit einer Stimme spricht' und unsere Sorgen in der UNO-Debatte, falls es dazu kommt, von Freunden als gemeinsame Sorgen vorgetragen würden. Mir scheint, daß der März-Termin [also die Debatte in den Vereinten Nationen] schwerer zu vermeiden sein wird als - bei Erfolg in dem skizzierten Bemühen - der Mai-Termin [der Unterzeichnung].“

Der CDU-Fraktionschef hatte in New York, wie mit dem Bundeskanzler verabredet, die Themen zur Sprache gebracht, die Bonn nach wie vor Kopfschmerzen bereiteten. Nach außen sollte, so schlug Barzel vor, der Eindruck vermittelt werden, als ob sich die Bundesregierung alles offenhalte und als ob bei den Verhandlungen in Genf zwischen den Supermächten erst eine „Diskussionsgrundlage“ und nicht ein fester Vertragstext bestehe ${ }^{67}$. Aber der letzte Satz in Barzels Brief deutet darauf hin, daß er selbst nicht mehr an einen günstigen Ausgang glaubte: „Alles ist offenbar sehr, sehr weit gediehen." Am Ende würde der Regierung vermutlich nichts anderes übrigbleiben, als zu unterzeichnen. Darüber gab man sich auch im Kanzleramt keiner Täuschung hin. Der Kanzler werde zustimmen, wenn sich Deutschland vor die Frage des Ja oder Nein gestellt sähe, erklärte Guttenberg Krone68.

\section{Abbruch der Verbandlungen um den Gewaltverzicht im Juli 1968 und Brandts verstärkte Bemühungen um Moskau}

Das war der Stand, als das Auswärtige Amt in seiner Aprilnote an Moskau den Beitritt der Bundesrepublik zum Sperrvertrag in Aussicht stellte. Doch die Offerte aus dem AA wurde in Moskau nicht honoriert. Die Sowjets verlangten mehr als Worte, wurden ungeduldig und wollten endlich konkrete Ergebnisse sehen. Am 5. Juli 1968 wies die So-

66 AdKASt, Kiesinger I - 226, D/IV.6, A 002, Barzel an Kiesinger vom 23.2.1968; dort auch die folgenden Zitate.

67 Vgl. BPA, Barzel im DLF am 17.3.1968, Anhang IV, S. 5: „Wir [...] [sind] in der Frage des NichtVerbreitungsvertrages weder in der Lage, jetzt ein Ja zu sagen noch ein Nein zu sagen, das ist erst 'ne Diskussionsgrundlage, und hier muß man erstmal sehen, wie das überhaupt in den Vereinten Nationen geht."

68 Vgl. Krone, Aufzeichnungen, S. 198. 
wjetunion daher mit zum Teil polemischen Aussagen die deutschen Ausführungen zurück. Sie selbst sei nur dann zu weiterem Meinungsaustausch über den Gewaltverzicht bereit, wenn die Regierung der Bundesrepublik konstruktiv und sachlich an dieses Problem herangehe, hieß es in dem Aide-mémoire. Die Sowjets hielten nicht nur an ihren Bedingungen fest, sondern jetzt kam erschwerend hinzu, daß sie plötzlich auf die sogenannten „Feindstaatenklauseln" der Charta der Vereinten Nationen (Art. 53, Zif. 1 und Art. 107) Bezug nahmen. Damit holten sie ein weiteres Instrument hervor, um Bonn in Zugzwang zu bringen. „Die Bestimmungen der UNO-Charta über Zwangsmaßnahmen,im Falle einer erneuten Aggressionspolitik', auf die sich die Regierung der BRD beruft, behalten voll und ganz ihre Bedeutung für die Bundesrepublik Deutschland“, hieß es ${ }^{69}$. Schließlich veröffentlichte die sowjetische Regierung eine Woche nach ihrem Aide-mémoire vom 5. Juli in der Izvestija an drei aufeinanderfolgenden Tagen den gesamten Text der sowjetischen Noten, die in den vergangenen Monaten der deutschen Seite übergeben worden waren. Im Gegenzug publizierte auch die Bundesregierung am 12. Juli ihre eigenen Noten.

Im Rückblick scheint die sowjetische Brüskierung mit den Vorgängen des Prager Frühlings in Verbindung gestanden zu haben ${ }^{70}$. So sieht das jedenfalls Brandt. Die Krise um die Tschechoslowakei habe damals schon eine dominierende Rolle in Moskaus Sicht gespielt ${ }^{71}$. Wahrscheinlich wurden die Sowjets auch von Ost-Berlin gedrängt, die Verhandlungen mit Bonn abzubrechen. Als erste sozialistische Partei hatte die SED den inneren Wandlungsprozeß der Prager Kommunisten bemerkt, verfolgt und verurteilt. Schon im Frühjahr 1964 (!) übte sie scharfe Kritik an der Kulturpolitik der Tschechoslowaken und brachte sogar den Fall ihres Dissidenten, des Physikers Robert Havemann, damit in Verbindung: Einige seiner revisionistischen Theorien stünden im Zusammenhang mit den Theorien, die aus Prag in die DDR gedrungen seien ${ }^{72}$.

${ }^{69} \mathrm{DzD}, 1968$, S. 973; siehe zum geschichtlichen Hintergrund Blumenwitz, Feindstaatenklauseln. $70 \mathrm{Vgl}$. Besson (Außenpolitik, S. 413 ff.), der erklärt, daß die Politik des Interventionsrechts auf eine Abwehrhaltung Moskaus gegenüber der deutschen Ostpolitik zurückzuführen ist, die noch verstärkt worden sei, je mehr sich die Situation in Prag zugespitzt habe. Mit dem sowjetischen Einmarsch in die ČSSR sei dann deutlich geworden, daß die Sowjetunion die Interventionsklauseln zum "Offensivinstrument" umfunktionierte. Moskau habe offenbar gehofft, sich ein Eingreifrecht im kapitalistischen Mitteleuropa zu schaffen. Das sei das sowjetische Motiv des dann folgenden „Trommelfeuers von Verleumdungen“ gegen die Bundesrepublik gewesen. Wettig (Die Sowjetunion, die DDR und die Deutschland-Frage, S. 56) setzt dagegen, daß der Prager Einmarsch die sowjetische Interventionspolitik unglaubwürdig gemacht habe. Der Sowjetunion sei es zuvor darum gegangen, mit dem Beharren auf der Intervention die Bundesrepublik von den Westmächten zu „isolieren“. Aber das Gegenteil habe sich dann gezeigt: Die Bündnispartner seien enger hinter Bonn zusammengerückt. Daraufhin habe sich der Kreml dazu entschlossen, wieder West-Berlin in den Mittelpunkt seiner Angriffe zu stellen.

$71 \mathrm{Vgl}$. Brandt, Begegnungen, S. 252. Man geht in der Historiographie davon aus, daß die Sowjetunion nicht wegen des Verhältnisses der Bundesrepublik zur CSSR in Prag einmarschiert ist; vgl. etwa Griffith, Ostpolitik, S. 160; Meissner, Die „Breshnew-Doktrin“, S. 621-642; Schulz, Die sowjetische Deutschlandpolitik, S. 278; Wettig, Das Vier-Mächte-Abkommen, S. 98. Dennoch hat es damals offenbar ein ernsthaftes Bemühen der Bundesregierung um die Verbesserung der Beziehungen zur ČSSR gegeben. So merkt Schulz (Prag und Bonn, S. 124) im Februar 1967 an: „Die Bundesregierung hat die Voraussetzungen für ein Arrangement geschaffen, das eine vernünftige Entwicklung der deutsch-tschechoslowakischen Beziehungen einleiten könnte und beiden Seiten die Möglichkeit gibt, ihr Gesicht zu wahren. Jetzt ist Prag am Zug." Siehe dazu auch Griffith, Ostpolitik, S. $159 \mathrm{f}$.

72 Vgl. Tudyka, Die DDR im Kräftefeld, S. 19. Havemann war im März 1964 aufgrund eines Interviews, das in der Zeitung Hamburger Echo erschienen war, aus der Partei ausgeschlossen worden. 
Was war von dem abrupten Schritt der Notenveröffentlichung durch die Sowjetunion zu halten? War die Ostpolitik der Großen Koalition fehlgeschlagen? Brandt glaubte nicht an ein Scheitern. Durch diesen Rückschlag sei eine Annäherung noch nicht blockiert, meinte er. Sein französischer Kollege bestärkte ihn in dieser Meinung. Am 20. Juli 1968 - genau einen Monat vor dem sowjetischen Einmarsch in Prag - trafen sich Brandt und der neue französische Außenminister, Michel Debré, in der französischen Botschaft in Brüssel zu einem ersten, längeren Gespräch. Debré behauptete dort, die Sowjets hätten zwei Hauptziele, die sich möglicherweise nicht vereinbaren ließen: erstens die Einheit des sozialistischen Lagers zu erhalten und zweitens die Entspannung zwischen Ost- und Westeuropa einzuleiten. Eine Harmonisierung der beiden Ziele und Politiken sei nur unter festen Bedingungen möglich. Und zwar mußte die Sowjetunion mit außerordentlicher Festigkeit auf der Beibehaltung des Status quo beharren und als grundsätzlicher Gegner jeder Revision der politischen Landkarte Europas auftreten. Nur wenn der Kreml in diesem Punkt eine kategorische Haltung einnähme, könne die Einheit des sozialistischen Lagers bewahrt und gleichzeitig die Entspannung vorangetrieben werden. „Die Grobheit der sowjetischen Antworten sei nur durch den Wunsch zu erklären, den Widerspruch zwischen den beiden politischen Zielen zu überwinden", heißt es wörtlich in dem Gesprächsprotokoll. „Der Herr Minister habe recht, wenn er diese Antwort nur als momentanes Ereignis in den Beziehungen ansehe, ausgelöst durch die Furcht, daß den Reformbestrebungen in Prag weitere Bewegungen in Polen und in Ostdeutschland folgen könnten. Der sowjetische Ton werde zwangsläufig um so schroffer sein, als die Dinge mehr in Bewegung gerieten."73

Der deutsche Außenminister fühlte sich ermutigt. Es war, als ob die brüske Moskauer Ablehnung ihn noch darin bestärkt hatte, den einmal eingeschlagenen Weg weiter zu verfolgen - egal, welche Hindernisse sonst noch auftauchen würden. Selbst die verlorenen Landtagswahlen, die vermutlich auf das Konto einer weitreichenden Ostpolitik gingen, konnten ihn jetzt nicht zur Umkehr bewegen. In Baden-Württemberg hatte die SPD am 28. April 1968 ein Desaster erlebt: Während die CDU sich um 2,1 Prozentpunkte verbesserte und insgesamt 44,1 Prozent auf sich vereinigen konnte, verlor die Sozialdemokratische Partei 8,2 Prozentpunkte. Nur noch 29,1 Prozent der Wähler stimmten dort für die SPD. Die rechtslastige NPD erhielt auf den ersten Schlag gleich 9,8 Prozent. Die SPD-Fraktion gab sich keiner Täuschung hin: 3 - 4 Prozent habe man durch den Parteitagsbeschluß zur Oder-Neiße-Grenze verloren, hieß es in der Bonner Fraktionssitzung am 29. April74.

Brandt sah jetzt, Ende Juli 1968, deutlicher als je zuvor, daß die einzig mögliche Offerte von deutscher Seite an die Sowjetunion in der Unterzeichnung des Nichtweitergabevertrages bestand. Der Kanzler würde keine der anderen, von Moskau genannten Bedingungen erfüllen wollen. Brandt mußte deshalb Kiesinger davon überzeugen, daß von dessen Unterschrift die Fortsetzung der Ostpolitik abhing. Nur durch diesen ersten Schritt

73 Archiv des AA, ZA 5-51, A/68, Aufzeichnung des Gesprächs vom 20.7.1968, S. 4. Im Auswärtigen Amt ahnte man längst, warum dieser erste Teil der Verhandlungen zu keinem Ergebnis geführt hatte. Bahr (Gespräch mit dem Verfasser, 4.7.1988) spricht von dem „aseptischen“ oder "zahnlosen" Angebot, das die Bundesrepublik der Sowjetunion unterbreitete. Ohne die Einschließung und Anerkennung der bestehenden Grenzen, so der Planungschef des AA, waren die Aussichten auf ein Ergebnis gering.

$74 \mathrm{Vgl}$. AdsD, Protokolle interner Sitzungen der Führungsgremien, SPD-Fraktionssitzung vom 3.5.1968, Ernst Haar in einer ersten Auswertung des baden-württembergischen Wahlergebnisses, S. 9. 
konnte die Bundesrepublik die nächste Hürde auf dem Weg zu Gewaltverzichtsabkommen mit der Sowjetunion nehmen.

\section{Brandt drängt Kiesinger zur Unterschrift}

Aber der Außenminister wußte auch, daß dies ein schwieriges Unterfangen werden würde. Denn Kiesinger baute immer höhere Hindernisse auf, von deren Beseitigung er die Unterschrift abhängig machen wollte. Am 5. Juli 1968 hatte sich der Kanzler öffentlich zu den Problemen geäußert, die vor einer Zustimmung durch die Bundesregierung befriedigend und einvernehmlich gelöst werden müßten. Er verband dabei geschickt das neue rauhe Klima, entstanden durch die Berlin-Krise und das Festhalten der Sowjets an den Feindstaatenklauseln, mit dem Ziel des Vertrages. Auf einer Pressekonferenz in Bonn machte er zunächst deutlich, daß vor einer endgültigen Festlegung der Bundesregierung die für August geplante Genfer Konferenz der kernwaffenlosen Staaten abgewartet werden würde. Besondere Bedeutung käme zudem der Frage zu, wie sich ein Unterzeichnerstaat gegen Pressionen oder Aggressionen eines nuklearen Staates wehren könne. Um sich vor solchen Gefahren zu schützen oder um auch nur eine mögliche Garantie zu erhalten, forderte Kiesinger von den beiden Supermächten eine detaillierte Interpretation des Vertragstextes. Falls die Sowjetunion dies verweigere, sagte mahnend der Kanzler, entstünde „ohne Z weifel eine völlig neue Situation" 75 . Der Kanzler zielte darauf, daß die Sowjets öffentlich erklären sollten, sie würden ihre im Vertrag festgeschriebene Sonderstellung nicht zur Durchsetzung von politischen Zwecken nutzen. Das war natürlich provokativ gemeint und sollte dem dauerhaften öffentlichen Druck der Sowjets auf die Bundesregierung in der Frage des Sperrvertrages etwas entgegensetzen 76 . Ein noch schärferes Geschütz fuhr Kiesinger einige Wochen später auf, als er in einem Interview erklärte, das Problem sei das schwierige Verhältnis zur Sowjetunion, die sich „außerordentlich unfreundlich - ja drohend - uns gegenüber verhält" ${ }^{\prime 7}$. Der Kanzler machte noch einmal die lauteren Absichten der Bundesregierung deutlich. Die Bundesregierung könne niemand verdächtigen, den Besitz nuklearer Waffen anzustreben, wenn sie ihre Haltung zum Vertrag genau überdenke. Die Bundesrepublik sei das einzige Land, das auf Herstellung und Besitz nicht nur nuklearer Waffen, sondern auch anderer Massenvernichtungsmittel schon 1954 verzichtet habe.

Brandt war da anderer Ansicht. „Der Atomverzicht von 1954 ist letztlich nie honoriert worden," meinte er in einem Schreiben an den Bundeskanzler vom 15. Juli. Nur drei Tage nachdem die Bundesregierung ihre Seite des Notenwechsels mit der Sowjetunion veröffentlicht hatte, sandte er ein umfangreiches Plädoyer zugunsten des Sperrvertrages an den Kanzler, der einen Kurzurlaub in Bebenhausen verbrachte. Mit der Einstellung zum Nichtverbreitungsvertrag stehe die Glaubwürdigkeit der Entspannungspolitik auf dem Spiel, argumentierte Brandt. Wenn Brasilien, Indien, Japan oder Schweden zögerten, dann werde das allgemein in der Weltöffentlichkeit bedauert, ändere aber

${ }^{75}$ Bulletin, 9.7.1968. Wörtlich sagte Kiesinger: „Ich habe volles Vertrauen, daß die amerikanische Seite die Interpretationen so geben wird, wie wir sie wünschen und erhoffen und wie sie zum Teil auch abgesprochen sind. Die Frage wird sein: Was wird die Sowjetunion dazu tun? Wenn sie diese Interpretationen ablehnt, dann entsteht ohne Zweifel eine völlig neue Situation."

76 Vgl. EA 23 (1968), Folge 15, S. Z 153. Der Sprecher der Bundesregierung, Diehl, hatte am 1.7. er-

klärt, die Bundesregierung wolle Probleme des Kernwaffensperrvertrages prüfen. Dazu zähle die

Tatsache, daß die Sowjetunion einen „massiven politischen Druck auf die Bundesrepublik Deutschland seit langem angesetzt hat und ihn auch gegenwärtig fortführt“.

77 Rheinische Post, 27.7.1968. 
nichts an der Wertschätzung, die diese Staaten genössen. „Wenn wir zögern, so wird das latente Mißtrauen, das bei unseren östlichen Nachbarn, aber auch bei manchen einflußreichen Kreisen im Westen gegenüber der Bundesrepublik und ihrer inneren Entwicklung vorhanden ist, neue Nahrung erhalten. " 78 Die östliche Propaganda werde dieses schwelende Feuer zu entfachen wissen.

Brandt drängte Kiesinger, schnell zu unterzeichnen. Jede Verzögerung führe zu nachteiligen Dauerwirkungen für die Bundesrepublik. Man laufe sonst Gefahr, wieder einmal eine Chance zu verpassen und den Gegnern einen „billigen Vorwand für ihre Propaganda" zu liefern. Die Gegengründe, die Kiesinger auf einer Pressekonferenz wenige Tage zuvor aufgeführt hatte, hielt der Minister für nicht überzeugend. Fragen zur amerikanischen Vertragsinterpretation könnten rasch geklärt werden. Auf der Genfer Konferenz der nicht-nuklearen Staaten im August würde die Bundesrepublik einen leichteren Stand haben, wenn sie bereits unterzeichnet hätte. Auch die Haltung anderer potentieller Nuklearmächte werde der Bundesrepublik ihre Entscheidung nicht erleichtern. „Niemand wird bereit sein, sich mit uns solidarisch zu erklären und uns zu verteidigen, wir bleiben allein", zeichnete Brandt ein düsteres Bild 79 . Er verwies darauf, daß die Brüsseler Kommission kurz zuvor festgestellt hatte, eine Unvereinbarkeit zwischen den Zielen des NV-Vertrages und denen der Europäischen Atomgemeinschaft liege nicht vor. Außerdem bliebe die Möglichkeit einer Atomstreitmacht, wie sie sich die Union wünsche, innerhalb einer zukünftigen europäischen Armee erhalten. Anderslautende Behauptungen seien daher gegenstandslos. Die Benelux-Staaten und Italien würden in den kommenden Wochen den Vertrag unterzeichnen. „Unter diesen Umständen spräche objektiv viel dafür, auch bei uns noch im Sommer die Voraussetzungen für die Unterschrift zu schaffen. Ich weiß, daß dies aus praktischen Gründen nicht einfach ist, zumal ein Kontakt mit den Führungen der Fraktionen erforderlich sein würde." Größte Bedenken hätte er, Brandt, dagegen, die Entscheidung weit in den Herbst hinein zu verlagern. Schon meldeten sich Stimmen, die anrieten, bis nach den amerikanischen Wahlen zu warten „praktisch ein für uns gefährliches Mißtrauensvotum gegen die jetzige USA-Administration und gegen die Mehrheit des Senats, mit der wir es weiter zu tun haben werden“. Andere wollten sich noch mehr Zeit nehmen. Dann käme man aber in den Sog des eigenen Wahlkampfes. Das könnte die Große Koalition zu einem Zeitpunkt zerbrechen lassen, da sie noch wichtige Aufgaben zu erfüllen habe ${ }^{80}$.

Brandt schreckte also nicht davor zurück, mit dem Ende der Koalition zu drohen. Auch die Warnung vor dem von der Sowjetunion aufgeworfenen Interventionsrecht durch die UNO-Charta hielt der Minister nicht für ein ausreichendes Gegenargument: Er habe die „allerstärksten Bedenken dagegen“, dies zu einem Grund für die Nichtunterzeichnung zu machen. Abgesehen davon, daß man diesen beiden obsolet gewordenen Paragraphen „eine ganz und gar unerwünschte Aktualität“ verleihe, würde dies „ein massives Mißtrauen gegenüber den USA“ bekunden. Der Außenminister faßte zusammen: Man solle sich auf die Unterzeichnung in allen drei Hauptstädten im Frühherbst 1969 einstellen ${ }^{81}$.

Drei Tage später fand eine intensive Aussprache mit Kiesinger im Gästehaus des Industriellen und CDU-Vorsitzenden in Nordwürttemberg Scheufelen in Stuttgart statt.

\footnotetext{
${ }_{78}$ AdKASt, Kiesinger I - 226, D/IV.6, A 001, Brandt an Kiesinger vom 15.7.1968.

79 Ebenda, S. 2.

80 Ebenda, S. 3.

81 Ebenda, S. 5.
} 
Dort vereinbarten beide, die endgültige Entscheidung bis nach der Genfer Konferenz der nicht-nuklearen Staaten Ende August 1968 zu verschieben. Brandt gab sich dennoch zuversichtlich. Er vertraute seinem französischen Kollegen an, in der Bundesrepublik sei zwar die Entscheidung über die Unterzeichnung noch nicht gefallen, alles spreche aber dafür, „daß zu einem geeigneten Zeitpunkt unterzeichnet werde“82.

Kiesingers Position wurde auch dadurch unhaltbarer, daß - wie Brandt im Brief erwähnte - die anderen Staaten der Europäischen Gemeinschaft dem Vertrag positiv gegenüberstanden. Außer der Atommacht Frankreich wollten alle den seit dem 12. Juni vorliegenden Vertrag über die Nichtverbreitung von Kernwaffen offenbar unterzeichnen. An diesem Tag hatten ihn nach siebenwöchiger Debatte 95 Staaten in der Vollversammlung der Vereinten Nationen gebilligt. Nur Albanien, Kuba, Sambia und Tansania hatten gegen ihn gestimmt, 21 Staaten sich der Stimme enthalten. Am 1. Juli 1968 setzten Washington, London und Moskau ihre Unterschrift unter den Vertrag. Das war Anlaß für Brandt, sich erneut beim Kanzler einzusetzen. Aus seinem Urlaubsort in Norwegen schrieb er mit der Hand am 10. August an Kiesinger, die Lage habe sich zu stark geändert, um die endgültige Entscheidung bis nach der Genfer Konferenz der NichtNuklearen zu verschieben. Man sei ja davon ausgegangen, daß die vier anderen EURATOM-Partner eine einheitlich ablehnende Haltung einnehmen würden. Das sei jetzt anders. Italien und die Benelux-Länder hatten inzwischen ihren positiven Standpunkt zum Vertrag erklärt. Belgien habe sogar seinen Botschafter in London angewiesen, am 19. August seine Unterschrift unter das Abkommen zu setzen. Hinzu komme, daß Frankreich in der Frage der europäischen Option zur Zurückhaltung geraten habe.

In der Tat hatte Außenminister Debré in dem schon zitierten Gespräch vom 20. Juli vor einer Erklärung gewarnt, welche die Deutschen gerne vor einer Unterzeichnung gemeinsam mit ihren westlichen Nachbarn abgegeben hätten. Darin sollte bestätigt und bekräftigt werden, daß der Sperrvertrag nicht den Prozeß der europäischen Einigung präjudizieren dürfe. Die Bundesregierung wollte damit die Möglichkeit einer atomaren Verteidigung der europäischen Union offen halten, an der sie selbst beteiligt war. Doch Debré riet von diesem Vorhaben ab. Denke man an eine europäische Einheit, die zu einer gemeinsamen Verteidigung führen würde, so liege diese in weiter Ferne. Die genannte Klausel würde also nicht in unmittelbarer Zukunft zum Tragen kommen, sondern höchstens auf lange Sicht. Der Nutzen würde sich also erst in Jahrzehnten auszahlen. Dagegen könne eine solche Erklärung jetzt die konservativen Kräfte in der Sowjetunion stärken. Ein solcher Vorbehalt würde diesen Entspannungsfeinden im Kreml nur ein zusätzliches Argument liefernn ${ }^{83}$. Es wurde deutlich, daß Frankreich selbst gegen den Vertrag war, aber es offensichtlich gerne sah, wenn sein östlicher Nachbar dem Vertrag dennoch beitrat.

Für Kiesinger bedeutete dies allerdings nicht, daß die Bundesregierung jetzt sofort zustimmen mußte. Der Kanzler hatte bestimmt, daß das Thema des NV-Vertrages in der Kabinettsitzung vom 27. August nicht abschließend behandelt werden sollte, wie das zuvor Brandt vorgeschlagen hatte. Dazu meinte der Minister jetzt, er sei auch nicht davon ausgegangen, daß eine abschließende Behandlung auf dieser Sitzung möglich gewesen wäre, zumal für die Bundesregierung erklärt worden sei, daß sie sich nach der Konferenz der nicht-nuklearen Staaten in Genf entscheiden werde. Brandt bezog sich hier auf

82 Archiv des AA, ZA 5-51, A/68, Aufzeichnung des Gesprächs vom 20.7.1968, S. 12. „Die Ratifizierung werde allerdings längere Zeit in Anspruch nehmen“, heißt es da.

83 Vgl. ebenda, S. $13 \mathrm{f}$. 
die Äußerung Kiesingers gegenüber der Zeitung Rheinische Post ${ }^{84}$. Er nahm diese Erklärung des Kanzlers jetzt zum Anlaß, zumindest auf eine Vorentscheidung zu drängen. Die Situation habe sich nun insoweit verändert, als die vier anderen EURATOM-Partner den Vertrag vor Beginn der Genfer Konferenz unterzeichnen wollten. Frankreich habe die Deutschen sogar in der Frage der europäischen Option zur Zurückhaltung geraten, betonte Brandt nochmals. „Insofern befinden wir uns in einer etwas schwierigen Lage: Eine außenpolitische Isolierung müssen wir vermeiden. Die innenpolitischen Schwierigkeiten, denen gerade Sie sich gegenübersehen, sind mir andererseits wohl bewußt." 85

Die Position der Bundesrepublik würde seiner Meinung nach in Genf unverantwortbar erschwert werden, „wenn wir unsere Haltung nicht plausibel machen können“. Deshalb sei es erforderlich, daß man am 27. August zu einer Vorklärung komme. Erstens müsse dort die grundsätzlich positive Haltung bestätigt werden, die die Regierung schon am 27. April des Vorjahres vor dem Bundestag eingenommen habe. Zweitens sollten die Bereiche gekennzeichnet werden, in denen man am Vertrag und seinem Beiwerk nichts mehr auszusetzen habe. Und drittens sollten dann die Punkte zusammengestellt werden, bei denen die Bundesregierung an einer über den Vertragstext hinausreichenden Klärung gelegen sei.

„Mit einer solchen Vorklärung können wir zur Not in Genf bestehen“, meinte Brandt. "Ohne sie würde ich jedenfalls meine Teilnahme nicht für ratsam halten." In diesem $\mathrm{Zu}$ sammenhang wolle er auch darauf hinweisen, daß die Unterlagen, die das Auswärtige Amt bzw. die interministerielle Arbeitsgruppe zum NV-Vertrag zusammengestellt habe, allen Kabinettsmitgliedern zugestellt werden sollten. Dies sei nicht mehr nur eine Sache des Verteidigungsrats, und ohne die NV-Unterlagen ließe sich die Marschroute für Genf nicht entwickeln.

Aber Kiesinger weigerte sich, ein grundsätzliches Votum oder auch nur eine Vorentscheidung über das Thema im Kabinett herbeizuführen. Der Kanzler hatte seit dem Frühjahr 1967 darauf gesetzt, die Sache immer weiter hinauszuschieben. Er hegte die Hoffnung, die internationale Entwicklung werde es gar nicht zu einer Vereinbarung der Supermächte kommen lassen. Tatsächlich lieferten ihm die Spannungen um Berlin ein $\mathrm{Ar}$ gument, das er als Erklärung für sein Zögern anführen konnte. Nur vier Tage vor dem Einmarsch Warschauer Pakttruppen in die Tschechoslowakei, am 17. August 1968, antwortete der Kanzler daher seinem Minister schriftlich:

"Ich bin mit Ihnen der Auffassung, daß die Absicht der übrigen vier nichtnuklearen EURATOM-Staaten, den Vertrag noch vor der Genfer Konferenz zu unterzeichnen, bedeutungsvoll ist. Die besondere deutsche Situation, die durch die Sowjetnote vom 5. Juli und die Berliner Maßnahmen der,DDR' erneut unterstrichen wurde, scheint mir jedoch eine von unseren EURATOM-Partnern abweichende Prozedur zu rechtfertigen."

Er sei auch damit einverstanden, in der Sitzung des Bundesverteidigungsrates (BVR) den gesamten Komplex des NV-Vertrages eingehend zu erörtern. Im Kabinett sollte jedoch die Diskussion möglichst auf jene Probleme beschränkt werden, die zur Meinungsbildung der Regierung zu der in Genf zu behandelnden Thematik notwendig seien. Eine allgemeine Diskussion über die Bewertung des NV-Vertrages anhand einer vom Auswärtigen Amt vorgelegten Unterlage werde dagegen zu einer Art Vorentscheidung

84 Vgl. Rheinische Post, 27.7. 1968.

85 AdKASt, Kiesinger I - 226, D/IV.6, A 001, Brandt an Kiesinger vom 10.8.1968, S. 2; siehe dort auch die folgenden Zitate. 
führen, „die meines Erachtens aus innen- wie aus außenpolitischen Gründen noch nicht möglich ist“. „Selbstverständlich sollte bei und nach dieser Kabinettsitzung die allgemeine grundsätzliche Haltung der Bundesregierung zum Nichtverbreitungsvertrag erneut bekräftigt werden. Mit Rücksicht auf die Klausurtagung der SPD am 26. August 1968 habe ich die BVR-Sitzung für den 27. August und die Kabinettsitzung für den 28. August 1968 festgesetzt.“ Kiesinger schloß mit der Bitte, „sich mit dem von mir vorgesehenen Ablauf der Beratungen im Bundesverteidigungsrat und im Kabinett einverstanden zu erklären" 86 .

Kiesinger konnte noch nicht wissen, daß ihm die Sowjetunion wenig später selbst das entscheidende Argument in die Hand geben würde. Der Einmarsch von Truppen des Warschauer Paktes in Prag erlaubte ihm, die Behandlung so weit hinauszuzögern, daß er nicht mehr in die Verlegenheit kommen sollte, eine endgültige Entscheidung zum Nichtverbreitungsvertrag treffen zu müssen.

\section{Der Prager Frübling}

Alles hatte in der ČSSR mit einer drastischen Verschlechterung der tschechischen Wirtschaft im Jahre 1963 begonnen. Die Wachstumsquote der Industrie lag 1960 noch bei 12 Prozent und nahm dann stetig ab: 1961 waren es noch 8,9 Prozent, 1962 nur noch 6,1 Prozent, und ein Jahr später fiel die Rate auf 0,4 Prozent. Zunächst bedeutete dies nichts anderes, als daß die Effektivität der Neuinvestitionen stetig zurückgegangen war und der Verfall von Produktion und Produktivität die Erwartungen auf einen Zuwachs voll aufzehrte ${ }^{87}$. Für ein stark industrialisiertes Land wie die C CSSR wirkte diese Bilanz jedoch alarmierend. Man mußte Wirkungen auf die Konkurrenzfähigkeit der Wirtschaft befürchten, einen Rückschlag im Bereich des technischen Wissens. Die tschechoslowakische Wirtschaft drohte den Anschluß zu verpassen. Die Aussicht erschien um so schmerzhafter, als es nach dem Krieg gelungen war, sich durch den bedingungslosen Ausbau der Schwerindustrie, gestützt auf die Vorkriegskapazitäten in der Stahlproduktion, vom neunten Platz (1937) auf die fünfte Stelle in der Welt hochzuarbeiten.

Den wirtschaftlichen Erfolg mußte die Bevölkerung des Landes allerdings mit politischer Monotonie und absoluter Treue zum Regime des sozialistischen Systems bezahlen. Im Jahre 1960, so hat der Journalist Hansjakob Stehle einmal geschrieben, habe man die ČSSR als „hoffnungsloses politisch-geistiges Ödland" empfunden ${ }^{88}$. Antonin Novotný, der mit diktatorischen Mitteln regierende Parteiführer, sah sich anläßlich wirtschaftlicher Schwierigkeiten daher nur zu einigen kleineren Reformen gezwungen: Die Grenzen wurden für westliche Besucher geöffnet, er gewährte eine größere kulturelle Freiheit - nach wie vor existierte aber eine Vorzensur. Auf dem wirtschaftlichen Sektor wurde ab 1966 versucht, eine Reform durchzuführen, die einige marktwirtschaftliche Elemente enthielt, ohne allerdings die bestehende Planwirtschaft zu ersetzen ${ }^{89}$. Es bildete sich in der KPČ ein Reformflügel, der einen "marktorientierten Sozialismus" forderte. Dabei sollte das gesellschaftliche Eigentum an den Produktionsmitteln mit einem Minimum an Planung und Preisfestsetzung und einem Maximum an unternehmerischer Freiheit kombiniert werden. Aber das Experiment führte bald zu einer Verschlechterung der

${ }^{86}$ AdKASt, Kiesinger I - 226, D/IV.6, A 001, Kiesinger an Brandt vom 17.8.1968.

87 Vgl. Otto, Neue Führung, S. 91.

88 Stehle, Nachbarn im Osten, S. 77.

89 Vgl. Šik, Prager Frühlingserwachen, S. 179; Šik, Leiter der Reformkommission, meint in seinen Erinnerungen, daß das Politbüro auf diese Weise die Reform habe langsam einschläfern wollen. 
wirtschaftlichen Lage, und im Juli 1967 hielten es die Planer der alten Schule für notwendig, Kontrollen einzuführen, um die Entwicklung wieder rückgängig zu machen ${ }^{90}$.

Ein weiteres Symptom der Unruhe, der Streit um größere kulturelle Freiheit, forcierte die Abwahl Novotnýs von seinem Amt als Erstem Sekretär der Kommunistischen Partei. Auf dem vierten Kongreß des Schriftstellerverbandes wagten es mehrere Autoren erstmals, Zensur und Parteikorruption anzuprangern ${ }^{91}$. Zur Stimmung gegen den Ersten Sekretär trug auch eine wachsende Verärgerung der slowakischen Kommunisten bei, auf deren Eigenständigkeit und Traditionen Novotný seit der von ihm verfügten Auflösung der slowakischen Regierung im Jahre 1960 immer weniger Rücksicht nahm ${ }^{92}$. Schließlich wurde er durch das Präsidium der Partei im Januar 1968 vom Amt des Ersten Sekretärs entbunden. Er blieb allerdings im Amt des Staatspräsidenten ${ }^{93}$. Als Nachfolger wurde der Slowake Alexander Dubček gewählt, ein bis dahin völlig unbekannter Funktionär94. Aber darüber hinaus änderte sich nichts. Die Inhaber blieben in ihren Parteiämtern, außer Novotný wurde kein Präsidiumsmitglied ausgewechselt. Der Vorgang hatte den Anschein, als ob sich ein Machtwechsel nur auf höchster Ebene vollzogen hatte, vergleichbar der Ablösung Chruschtschows in Moskau 1964.

Doch der Schein trog, und es geschah etwas Unvorhergesehenes: Von unten setzte ein Säuberungsprozeß der Partei ein, der von der Parteiführung wenig gebremst wurde, weil es den Zielen Dubček zunächst entsprach, eine Auflockerung der Parteistruktur zu erreichen ${ }^{95}$. Als größten Erfolg konnte diese Bewegung am 18. Februar den Sturz des Chefs der berüchtigten 8. Abteilung im Zentralkomitee, Miroslav Mamula, verbuchen. Er hatte die Polizei und die Armee befehligt. Beschleunigt wurde die in Gang gesetzte Demokratisierung auch durch die Flucht des Generals Jan Šenja, eines der höchsten Geheimnisträger des Prager Verteidigungsministeriums, samt seiner Geliebten nach Amerika. Von ihm hieß es, er habe nicht nur Gelder in großem Maße unterschlagen, sondern nur durch seinen Einsatz sei auch Novotný im Amt Staatspräsidenten gehalten worden ${ }^{96}$.

Im Februar 1968 war klar, daß sich die Novotný-Gruppe nicht länger an der Parteispitze würde halten können. Am 22. März erklärte der Präsident tatsächlich seinen Rücktritt. Einen Tag später mußte sich Dubček in Dresden für den neuen Kurs vor den Führern der sozialistischen Bruderstaaten rechtfertigen. Dabei wurde ihm nicht nur mit

90 Vgl. Viney (Der Demokratisierungsprozeß, S. 424): „Die Lockerung der Preisvorschriften führte im Jahre 1967 nur zu einem Ansteigen der Großhandelspreise, nicht jedoch zu einem wirksamen Druck auf die weniger produktiven Betriebe; die Bestände an unverkäuflichen Waren wuchsen weiter, die Lieferfristen wurden noch länger und die Vergeudung von Material noch größer." Siehe auch Otto, Neue Führung, S. $91 \mathrm{f}$.

91 Vgl. Šik, Prager Frühlingserwachen, S. $191 \mathrm{ff}$

92 Vgl. Viney, Der Demokratisierungsprozeß, S. 435 f.

93 Vgl. Möller (Das Scheitern, S. 669), der hier den ersten Kompromiß des Reformprozesses sieht. Eine Gruppe von Spitzenfunktionären hätte geglaubt, daß das Übel in der Kumulation der Ämter gelegen habe. Lediglich die Abwahl Novotnýs vom Posten des Parteiführers würde genügen, um dieses Manko zu beheben. Für die Abwahl vom Staatspräsidenten sei dagegen eine Nationalversammlung zuständig, erklärten sie. Es sei bemerkenswert, schreibt Möller, daß hier Kommunisten sich mit dem Hinweis von der Macht zurückzogen hätten, die Machtfülle des tschechoslowakischen Präsidenten sei faktisch größer als die des Ersten Sekretärs des Zentralkomitees der Partei. Über seinen Beitrag zur Ablösung Novotnýs siehe die Schilderung Šiks (Prager Frühlingserwachen, S. $214 \mathrm{ff}$.).

94 Vgl. Shawcross, Dubček.

95 Vgl. Möller (Das Scheitern, S. 671), der auf die demokratische Tradition der Tschechoslowaken verweist, die daher politisch weniger „apathisch“ seien als andere osteuropäische Völker.

96 Vgl. Viney, Der Demokratisierungsprozeß, S. 426; Šenja war ein enger Freund des Sohnes von Novotnný. 
Worten bedeutet, daß die Sowjetunion und die anderen Blockländer der politischen Entwicklung in der ČSSR skeptisch gegenüberstünden. Unbemerkt von der Weltöffentlichkeit waren sowjetische und andere Truppen des Paktes an der Grenze zur ČSSR zusammengezogen worden. Wie die neuen tschechoslowakischen Führer meinten, hing für kurze Zeit ihr Schicksal davon ab, ob die konservativen Funktionäre des Novotný-Apparates sich auf eine Person einigen konnten, die, wie 1956 in Ungarn Janos Kádár, mit allen Mitteln die Entwicklung „zurückdrehen“ könnte. Aber die Konservativen vermochten sich nicht auf eine Führungsfigur festzulegen. Für die sowjetische Führung schien zudem der vorgesehene Nachfolger Novotnýs im Präsidentenamt, General Ludvik Švoboda, ein Faktor der Stabilisierung zu sein. Auch der künftige Ministerpräsident Oldřich Černik besaß das Vertrauen Moskaus97.

Die Reformbewegung hatte bis zu diesem Zeitpunkt noch kein ausgearbeitetes Parteikonzept. Es existierten lediglich vereinzelt Vorstellungen, wie sich eine sozialistische Demokratisierung vollziehen könnte. Dazu zählten Maßnahmen wie die Einführung des Rechts auf relative Pressefreiheit, das Bemühen um Rechtssicherheit überhaupt, eine Rehabilitierung der Opfer des stalinistischen Herrschaftssystems und die Stärkung des Föderalismus durch die Übertragung von Rechten und Pflichten auf die Teile Böhmen, Mähren und der Slowakei. Immerhin lag bereits ein Aktionsprogramm vor, das im April vom Plenum des ZK gebilligt wurde und wenig später als Regierungserklärung auch das Parlament passierte. Besonders ein Punkt darin beunruhigte die sozialistischen Bruderländer. Er stellte die in den sozialistischen Ländern verfassungsrechtlich verankerte führende Position der Partei in Frage. Wörtlich lautete der Text: „Die Kommunistische Partei stützt sich auf die freiwillige Unterstützung des Volkes: sie realisiert ihre führende Rolle nicht dadurch, daß sie über die Gesellschaft herrscht, sondern dadurch, daß sie auf das ergebenste ihrer fortschrittlichen sozialistischen Entfaltung dient. Ihre Autorität kann sie sich nicht erzwingen, sondern muß sie unaufhörlich durch ihre Taten gewinnen. ${ }^{998}$ Diese Sätze fanden sich auch im Juli 1968 in der mutigen, aber etwas waghalsigen Antwort auf ein Schreiben der sogenannten „Warschauer Fünf“ - also der Sowjetunion, der DDR, Polens, Ungarns und Bulgariens. Darin wurde Dubček Führungsmannschaft angeklagt, sie versäume es, „konterrevolutionäre Tendenzen“ im Zaume zu halten. Es sei eine Situation entstanden, in der die "gemeinsamen Lebensinteressen der übrigen sozialistischen Länder" gefährdet seien"9.

Vorausgegangen waren Monate, in denen Regierung, Presse und Öffentlichkeit die Meinungsfreiheit in vollen Zügen genossen und ein Tabu nach dem anderen gebrochen hatten. Im Mai war beispielsweise verkündet worden, daß unpolitische Gruppierungen sich ab jetzt auch außerhalb der bis dahin vorgeschriebenen staatlichen Rahmenorganisation Nationale Front zusammenfinden dürften. Außenpolitisch sollten neue Akzente gesetzt werden. Es wurde vorgeschlagen, diplomatische Beziehungen zu Israel aufzunehmen. Man wollte sich stärker an Jugoslawien und Rumänien, die beiden eigenwilligen sozialistischen Staaten, anlehnen. Selbst die Beurteilung der von der Sowjetunion verteufelten Bundesre-

97 Vgl. Möller, Das Scheitern, S. 672 f.; Šik (Frühlingserwachen, S. 228) ist der Meinung, daß der äußere Druck auf die ČSSR die Entwicklung im Innern unnötig radikalisierte. Die Angst vor reaktionärer Rückentwicklung habe zur spontanen Entstehung von politischen Vereinigungen geführt.

98 EA, 23 (1968), Folge 13, Regierungserklärung vom 24.4.1968, S. D 306 ff.; vgl. auch Möller, Das Scheitern, S. 673.

99 EA 23 (1968), Folge 16, Gemeinsamer Brief der kommunistischen Parteien der Sowjetunion, Polens, der DDR, Ungarns und Bulgariens an das ZK der KPC vom 15.7.1968, S. D $388 \mathrm{ff}$. 
publik sollte einer vorsichtigen, freundlicheren Wandlung unterzogen werden ${ }^{100}$. Im Juli 1968 war die Sowjetunion nicht länger bereit, diese Entwicklung tatenlos mit anzusehen. In Warschau versammelte sich die Front der Gegner. Dubček blieb "mutig aus Furcht" 101 dem Treffen fern. Auf einen Brief aus Warschau, der einige Vorwürfe an die Prager Führung auflistete, erwiderte man mit protestantischer Entschlossenheit: Hier stehen wir und können nicht anders! Ohne etwas zurückzunehmen, verteidigte die KPČ ihren Kurs. Sogar auf die Gefahr einer möglichen Intervention durch den Warschauer Pakt ging die Prager Führung ein. Man warnte davor, und in dem Schreiben vom 19. Juli hieß es, man betrachte ,jeglichen Druck, der der Partei ein anderes Vorgehen aufzuzwingen sucht, [...] als die Hauptgefahr für die erfolgreiche Stärkung der führenden Rolle der Partei in der CSSR “102.

Bis jetzt war der Kreml davor zurückgeschreckt, das Mittel der Intervention einzusetzen, obwohl Anfang Mai dieser Vorgang bereits mit den sozialistischen Nachbarstaaten abgesprochen worden war ${ }^{103}$. Aber seit der Antwort der Prager Führung bereitete die Sowjetunion auch propagandistisch den Einmarsch vor. Am 19. Juli behauptete die Prawda, die tschechoslowakischen Sicherheitsbehörden hätten in der Nähe der Grenze zur Bundesrepublik ein Versteck amerikanischer Waffen gefunden, dies aber nicht gemeldet. Zwei Tage später berichtete das Zentralorgan der KPdSU, aus der Bundesrepublik strömten „Diversanten“, also Saboteure, in die ČSSR. In den folgenden Tagen richtete Moskau heftige publizistische Angriffe gegen einzelne tschechische Führer. Auch das Militär wurde jetzt mehr oder minder deutlich öffentlich ins Spiel gebracht. Der Tagesbefehl der sowjetischen Marine enthielt am 28. Juli den Hinweis, schweres Geschütz solle gegen „imperialistische Versuche“ aufgefahren werden, die „einen Einbruch in das sozialistische System erzwingen" wollten ${ }^{104}$. Schließlich wurden Manöver in den gesamten Westgebieten der UdSSR angekündigt. Sie sollten bis zum 10. August andauern.

Dieser propagandistisch vorbereitete Aufmarsch geschah hinter einer offensichtlich verhandlungsbereiten sowjetischen Führung. In Cierná traf sie sich mit dem Präsidium der KPČ vom 29. Juli bis zum 2. August 105. Es ging ihr darum, die konservativeren Mitglieder gegen Dubček auszuspielen ${ }^{106}$. Dazu wollten diese sich jedoch nicht hergeben. Die Sowjets schienen von der tschechischen Führung nun zu erwarten, daß der Prozeß der Liberalisierung eingeschränkt werde. Das sogenannte Preßburger Kommuniqué vom 3. August, wo sich zu den beiden Verhandlungsgruppierungen noch die Führer der an-

100 Vgl. Viney, Der Versuch der Re-Kolonisierung, S. 812. Das waren nur einige der neuen Gedanken. Es gab auch Gerüchte über eine französische Kapitalanleihe, und Sik verkündete am 16.5., daß man an Moskau mit der Bitte um eine Anleihe konvertierbarer Währung von 500 Mio. Dollar herangetreten sei.

101 Stehle, Nachbarn im Osten, S. 88.

102 EA 23 (1968), Folge 16, S. D 399; vgl. Šik, Frühlingserwachen, S. 256.

103 Vgl. Möller, Das Scheitern, S. 675.

104 Viney, Der Versuch der Re-Kolonisierung, S. 815.

105 Vgl. Sik (Frühlingserwachen, S. 257): „Das Mißtrauen unseres Politbüros in diesen angespannten Wochen und Tagen, das sich unter anderem darin äußerte, daß es nicht gewillt war, vollzählig in die Sowjetunion zu reisen (ein Mißtrauen, das sich später als durchaus berechtigt erwies), aber umgekehrt auch die Ablehnung des sowjetischen Politbüros, vollzählig in eine weiter entfernte tschechoslowakische Stadt zu fahren, führte zu der Kompromißlösung, ein Zusammentreffen an der Grenze zwischen beiden Staaten zu arrangieren. In einem kleinen Sitzungssaal des Eisenbahnerhauses in Cierná fanden die Sitzungen tagsüber statt, während beide Gruppen in bereitgestellten Eisenbahnschlafwaggons übernachteten, wobei sich die sowjetischen Waggons hinter die Grenze auf sowjetisches Territorium zurückzogen."

106 Vgl. Möller (Das Scheitern, S. 676), der allerdings anmerkt, daß sich bei den Gesprächen eine Uneinheitlichkeit der Prager Führung gezeigt habe. Es habe der Eindruck entstehen müssen, als ob sich das Präsidium in zwei Fraktionen spalten ließe. 
deren Warschauer Paktstaaten - ohne Rumänien - hinzugesellt hatten, drückte die Erwartung auf einen künftig wieder harten Kurs der KPČ aus. Die Unterzeichner ließen keinen Zweifel an dem Element der „führenden Rolle der Arbeiterklasse und ihrer Avantgarde, der kommunistischen Parteien" auf dem Weg zum Sozialismus. Sie räumten allerdings ein, daß bei jeder Bruderpartei die "nationalen Besonderheiten und Bedingungen berücksichtigt" werden müßten. Andererseits - und im Rückblick war das die Rechtfertigung für den Einmarsch - hieß es an einer anderen Stelle des Textes: Es sei die "gemeinsame internationale Pflicht aller sozialistischer Länder", die Errungenschaften des Sozialismus, „die dank der heldenhaften Anstrengungen und der selbstlosen Arbeit eines jeden Volkes erkämpft“ worden seien, „zu unterstützen, zu festigen und zu verteidigen "107. Dubček und seine Genossen wollten allerdings von einer Drohung nichts wissen, die man aus dem Text durchaus herauslesen konnte. Hand in Hand mit Breschnew ließ Dubček sich auf dem Balkon des Preßburger Rathauses von der Menge feiern. Man könne recht zufrieden sein, meinte er am selben 3 . August im Rundfunk. Die sowjetischen Genossen hätten sich davon überzeugen lassen, daß man gemeinsam die Grundsätze des Sozialismus verteidige. Er sei gefragt worden, ob die Souveränität des Landes gefährdet sei. Er wolle offen sagen, daß das nicht der Fall sei ${ }^{108}$.

Falls die Sowjets gehofft hatten, Dubček werde wieder eine strengere Zensur einführen, einen härteren Kurs ankündigen und die Diskussion um den Weg des demokratischen Sozialismus in andere Bahnen lenken, mußten sie sich allerdings bald eines Besseren belehren lassen. Am 8. August erschienen in einer tschechoslowakischen Literaturzeitung Beschwerden über eine sowjetische Einmischung in innerstaatliche Angelegenheiten. Zwei Tage später wurde der Entwurf für ein Parteistatut veröffentlicht, das den Mitgliedern das Recht auf Widerspruch gegen Beschlüsse einräumte und geheime Abstimmungen vorsah. Das Statut sollte dem Parteitag im September vorgelegt werden. Damit nicht genug, mit Tito und Ceauçescu besuchten ausgerechnet jene Führer nacheinander Prag, die für ihr Land jeweils eine größere Unabhängigkeit im Ostblock beanspruchten. Es entstand der Eindruck, als ob sich eine Front gegen die sowjetische Führungsposition bildete, die eines Tages auch Ungarn beeinflussen und schließlich dazu führen konnte, daß der gesamte südliche Gürtel des Warschauer Paktes von Moskau abfallen würde ${ }^{109}$.

Als Grund für den Einmarsch berief sich die sowjetische Propaganda aber schon Wochen zuvor auf die sogenannten „revanchistischen Pläne“ der Bundesrepublik. Die halbamtliche Zeitung Izvestija beschuldigte Bonn am 14. August, einen begrenzten Krieg gegen die DDR und die ČSSR vorzubereiten ${ }^{110}$.

107 EA 23 (1968), Folge 16, S. D 402; vgl. Stehle (Nachbarn im Osten, S. 93), der behauptet, daß hier im Kern die spätere Breschnew-Doktrin vorweggenommen worden sei; Viney (Der Versuch der Re-Kolonisierung, S. 816) bestreitet allerdings, daß es im Kommuniqué irgendeinen Bezug auf die mögliche Intervention gegeben habe. Es sei ein "ganz und gar vages Dokument voller Plattitüden“ und sei auf die „konkrete Situation in der Tschechoslowakei“ überhaupt nicht eingegangen.

108 Vgl. Viney, Der Versuch der Re-Kolonisierung, S. 816.

109 Vgl. ebenda, S. 818. Im tschechoslowakisch-rumänischen Freundschaftsvertrag fehlte der sonst übliche Hinweis auf die deutsche Gefahr. Wenige Stunden nach der Unterzeichnung des Vertrages am 16.8. erklärte ein "gut unterrichteter" osteuropäischer Journalist dem Korrespondenten Stehle (Nachbarn im Osten, S. 99), jetzt sei der Geduldsfaden Moskaus gerissen; in Kreisen der Militärattachés in Prag sei die Klage zu hören, daß die sowjetischen Kameraden schon kaum mehr vernünftig ansprechbar und auf eine "militärische Lösung des tschechoslowakischen Problems" versessen seien.

110 Vgl. Schulz, Die sowjetische Deutschlandpolitik, S. 279; Griffith (Ostpolitik, S. 160) schreibt, die Anklagen gegen den Bonner Revanchismus seien bewußt übertrieben worden. 


\section{Die Zerschlagung des Prager Früblings 1968}

Der Einmarsch von Truppen des Warschauer Pakts kam für die Bundesregierung überraschend. Die Geheimdienste versagten vollständig - genau wie 1961, als die Nachricht vom Bau der Berliner Mauer die westlichen Regierungen unvorbereitet getroffen hatte. Eine sowjetische Reaktion auf den mit dem Sturz des Parteiführers der tschechoslowakischen KP, Novotný, im Januar 1968 eingeleiteten Liberalisierungsprozeß in der Tschechoslowakei war zwar befürchtet worden. Trotzdem ahnte im Kanzleramt niemand etwas, als in der Nacht vom 20. auf den 21. August 24 Divisionen in die ČSSR einfielen ${ }^{111}$. $\mathrm{Ab} 23 \mathrm{Uhr}$ marschierten die Truppen. Erst gegen $1.15 \mathrm{Uhr}$ verbreitete die Nachrichtenagentur $D P A$ an sechster Stelle die Meldung über einen angeblichen Einmarsch. Um 2.25 Uhr kam eine entsprechende Blitzmeldung über den Fernmelder. Jetzt erst reagierte das Bundespresseamt. Der Kanzler wurde um 2.30 Uhr nachts geweckt, die Bundeswehr aber erst eine halbe Stunde später informiert. Die meisten Minister befanden sich im Urlaub. Schröder wurde aus seinem Ferienhaus auf Sylt nach Bonn gerufen. Brandt hatte noch weiter im Norden Erholung gesucht. Der Außenminister wurde von seinem Staatssekretär beim Fischen in nordnorwegischen Fjorden vor Narvik aufgestöbert. Mit Schiff, Wasserflugzeug und einer Bundeswehrmaschine brachte man ihn zurück nach Bonn ${ }^{112}$.

Wie verletzlich die Bundesrepublik gegenüber einem sowjetischen Angriff war, wurde Kiesinger erst durch diese Intervention bewußt. Warum denn die tschechischen Soldaten nicht geschossen hätten, fragte er bei der Lagebesprechung den Generalinspekteur Ulrich de Maizière. Die tschechische Heeresführung sei nach vorliegender Information einem entsprechenden Befehl ihrer Regierung gefolgt, meinte de Maizière. Außerdem sei der Zeitpunkt des Einmarsches taktisch so überraschend gewesen, daß wahrscheinlich die meisten tschechischen Soldaten in dieser Nacht in ihren Kasernen geschlafen hätten ${ }^{113}$. „Ich hoffe, daß die Bundeswehr in einer ähnlichen Lage nicht in ihren Betten liegt und schläft", bemerkte Kiesinger spitz. Darauf antwortete ihm der anwesende Staatssekretär von Hase: „Herr Bundeskanzler, ob die Bundeswehr in einer solchen Lage in ihren Betten liegt oder nicht, ist eine politische, und nicht eine militärische Entscheidung." 114

Die Sorge des Kanzlers schien berechtigt. Plötzlich standen in Mitteleuropa, an der Grenze zu Bayern, nicht mehr 24, sondern insgesamt 48 Divisionen des Warschauer Paktes. Hinzu kam, daß Anfang September Moskau Bonn mit Vorwürfen und Anschuldigungen überzog. Die Sowjets rechtfertigten sogar den Einmarsch mit dem Hinweis, man habe verhindern wollen, daß die Bundesrepublik die Tschechoslowakei vereinnahmen

111 Vgl. Osterheld, Gespräch mit dem Verfasser, 6.10.1988, und Ivan Pfaff, Der Prager Frühling einmal anders beleuchtet, in: Frankfurter Allgemeine Zeitung, 2.7.1988. Die Intervention war schon in den letzten Maitagen 1968 von Moskau vorsorglich beschlossen worden.

112 Vgl. Der Spiegel, 26.8.1968, S. 33.

113 Vgl. Šik, Frühlingserwachen, S. 258. Šik stimmt der Behauptung nicht zu, daß der Prager Führung als Antwort auf den Einmarsch eine militärische Option geblieben wäre. „Wir hätten ja unsere militärischen Verteidigungskräfte, statt ihrer Konzentration gegen die kurze Grenze mit kapitalistischen Staaten, entlang unserer langen Grenzen gegenüber allen sozialistischen Nachbarstaaten postieren müssen und alle - zu einer erfolgreichen Verteidigung nötigen - materiellen und ideellen Vorbereitungen treffen müssen. Ohne ein militärischer Stratege zu sein, mußte ich mir sagen, daß jetzt, bei dieser Truppenkonzentration an unseren Grenzen, an so etwas nicht mehr zu denken war."

114 Maizière, In der Pflicht, S. 300. Später wandte sich Kiesinger an de Maizière und erklärte: „In diesen Tagen hätte der Fall eintreten können, daß ich den Oberbefehl über die Streitkräfte hätte übernehmen müssen. Darauf bin ich nicht vorbereitet. Wir müssen uns häufiger sehen." 
würde. Botschafter Zarapkin überbrachte am 2. September ein Papier, das in schärfster Form der deutschen Ostpolitik eine Absage erteilte. Darin forderte die Sowjetunion den Verzicht auf eine deutsche Verständigungspolitik gegenüber den osteuropäischen Staaten. Diese Forderung war mit einer Drohung verbunden: Wenn die deutsche Ostpolitik fortfahre, die Einheit der sozialistischen Staaten zu untergraben, würden daraus „Folgerungen gezogen“. Moskau enthielt sich einer Spezifizierung. Aber es beschuldigte Bonn, für die Aktion in der ČSSR mitverantwortlich zu sein. Die Bundesregierung habe die tschechoslowakischen Reformer unterstützt. Kurz gesagt: Die Politik der Annäherung an osteuropäische Staaten wurde als Einmischung in den sowjetischen Bereich betrachtet. Hier müsse eine völlige Kehrtwendung einsetzen, sonst werde die Sowjetunion „Konsequenzen" ziehen ${ }^{115}$.

\section{Gibt es eine Mitschuld Bonns am sowjetischen Einmarsch?}

Die Beschuldigung aus Moskau, daß die Bundesregierung die Intervention mitprovoziert habe, wies der Kanzler zurück. Er habe sich beim Thema ČSSR öffentlich stets zurückgehalten und die Entwicklung zwar durchaus positiv eingeschätzt, aber auch sorgfältig auf die Einhaltung der Nichteinmischung hingewiesen. So geschehen etwa Ende Juli 1968, als Kiesinger erklärte: „Wir beobachten das Geschehen mit größter Aufmerksamkeit. Wir halten uns dabei strikt an das Prinzip der Nichteinmischung, und wir wären glücklich, wenn alle anderen Staaten dasselbe täten. “116

Tatsächlich hatte die Bundesrepublik auf die Avancen der neuen tschechoslowakischen Führung im Juli 1968 zumindest öffentlich nicht reagiert ${ }^{117}$. So stellten die Tschechoslowaken der Bundesregierung eine Kompetenzerweiterung für die im Jahr zuvor mit dem Novotný-Regime vereinbarte Handelsmission in Aussicht. In der Mission könnten künftig auch Visa ausgestellt werden, hieß es. Darüber hinaus bot Prag Bonn die volle Aufnahme diplomatischer Beziehungen für 1969 an. Zwar beharrten die Tschechoslowaken auf der Anerkennung der DDR durch die Bundesrepublik, aber man stellte kein Junktim zwischen diesem Schritt und der Aufnahme von Beziehungen her. Damit hob man sich entscheidend von den anderen sozialistischen Staaten ab ${ }^{118}$. Die ČSSR wollte sogar auf sowjetische Hilfsgüter verzichten, falls die Bundesregierung ihr einen Millionenkredit gewähren würde. Aber Kiesinger weigerte sich, den Sowjets durch aktive Parteinahme für die tschechoslowakischen Reformer einen einfachen Vorwand zu liefern, um die Prager Bewegung etwa mit einem militärischen Schlag zu beenden. Er hätte das als „tölpelhaftes Benehmen " verstanden ${ }^{119}$.

Kiesinger lehnte daher jede deutsche Mitschuld am Einmarsch ab, intern mutmaßte er allerdings, daß Brandt den Sowjets dennoch Gründe geliefert haben könnte. Den Kanzler ärgerte es, daß es ihm nicht gelang, vertrauliche Kontakte zu wichtigen Mitgliedern des Auswärtigen Amtes an der Koblenzer Straße aufzubauen und zu unterhalten. Das

115 Die Welt, 4.9.1968. Vgl. auch Krone (Aufzeichnungen, S. 199): „Rasner zeigt mir das Papier, das dem Gespräch Zarapkins mit dem Bundeskanzler zu Grunde lag. Was die Zeitungen berichteten, stimmt mit dem überein, was ich las." Das Papier wurde nicht veröffentlicht.

116 Rheinische Post, 27.7.1968.

117 Siehe Seibt (Deutschland und die Tschechen) zur Vorgeschichte.

118 Vgl. Möller, Das Scheitern, S. 676 f. In Prag habe man nicht den Status quo einfrieren wollen, sondern man habe geglaubt, daß eine solche Anerkennung das Verhältnis zwischen Ost und West, speziell der Bundesrepublik zur DDR, verbessern würde. Ohnehin habe dort nicht der Eindruck vorgeherrscht, daß eine Vereinigung beider deutscher Staaten in einem Nationalstaat möglich sei, noch habe man sie für wünschenswert gehalten.

119 Der Spiegel, 15.7.1968, S. 21. 
Kanzleramt fand keinen Zugang. Auch seinem außenpolitischen Berater, Horst Osterheld, selbst dem früheren AA-Staatssekretär Carstens sei das nicht gelungen, klagte Kiesinger in vertraulichem Gespräch. Er hatte also weder Einblick in die Vorgänge, noch konnte er kontrollierend wirken. Notwendig erschien ihm ein solcher Zugang allerdings: Das einzige Mal, daß ihm etwas zugespielt worden sei, berichtete er viele Jahre später, habe es sich um ein Telegramm von Herrn Jiři Hájek, dem tschechischen Außenminister, an Brandt gehandelt. Es sei plötzlich auf seinem Schreibtisch gelandet, während der Tschechenkrise - „als es schon lichterloh brannte“. Hájek habe sehr bedauert, daß er die Begegnung mit Bahr nicht ermöglichen könne, hieß es da, er müsse gleich durchfliegen nach New York. Kiesinger ließ daraufhin Brandt kommen und verlangte Auskunft. Brandt habe in solchen Fällen immer unschuldig getan, erläuterte Kiesinger. Er wisse von nichts, er müsse sich erkundigen. Das sei ganz harmlos. Bahr habe den Hájek in Frankfurt auf dem Flughafen betreuen sollen. Darauf habe Kiesinger gemahnt: „An Ihrer Stelle würde ich eine solche Betreuung durch den Chef des Protokolls machen lassen und bei einer solchen kritischen Situation erwarte ich von Ihnen, daß Sie so etwas mit mir besprechen!" 120

Brandt hat sich noch in seinen Memoiren gegen den Vorwurf gewehrt, daß die Bundesrepublik der Sowjetunion leichtfertig einen Vorwand zum Eingreifen geliefert habe. Der Besuch des FDP-Vorsitzenden Scheel in Prag sei vielleicht überflüssig gewesen, räume er ein. Aber die Visite des Bundesbankpräsidenten Karl Blessing, der über den Ausbau der bilateralen Beziehungen nach der Einrichtung von Handelsmissionen sprechen wollte, habe "nicht die Spur von Feindseligkeit" gegenüber der Sowjetunion enthalten ${ }^{121}$. Diese Erklärung erscheint allerdings, besonders da sie im Rückblick verfaßt wurde, geradezu naiv - eine Naivität, die auch Kiesinger an Brandt wahrnahm und ihm nicht verziehen hat. Der Kanzler habe im Kabinett ausdrücklich vor Reisen in die ČSSR zu jenem Zeitpunkt gewarnt, berichtet Guttenberg ${ }^{122}$. Den Besuch Scheels konnte er allerdings nicht verhindern. Er habe ihm zwar nichts zu befehlen, erklärte Kiesinger Scheel in einem Gespräch kurz vor der Abreise des Liberalen, „aber sehen Sie nicht, daß Sie den Russen geradezu das Argument in die Hand spielen, das sei eine Verschwörung zwischen uns und nicht nur die Russen, [auch] die Franzosen werden dasselbe sagen?" ${ }^{123}$ Mit demselben Argument suchte der Kanzler Blessing zurückzuhalten. Wenn der Präsident der Bundesbank nach Prag fahre, dann heiße es doch gleich: der finanziert Dubček gegen Moskau. Blessing verteidigte sich mit den Worten, das Ganze sei mit dem Herrn Außenminister abgesprochen, „der begrüßt das sehr“.

Daß der Außenminister solche Reisen von Politikern aus der Bundesrepublik nach Prag tatsächlich befürwortete, wurde dem Kanzler von seinem Minister selbst bestätigt, als sich beide im Juli 1968 in Stuttgart trafen, um über den Sperrvertrag zu sprechen. Am Ende des Gesprächs erklärte der Minister beiläufig, er müsse noch den Bundestagsabgeordneten Ernst Paul in Esslingen besuchen, einen Sudetendeutschen. Der fliege am näch-

120 AdKASt, Kiesinger I - 226, F/3., A 322, Gespräch mit Löwe, 31.1.1978, S. 13 f. Brandt rechtfertigt sich in seinen Erinnerungen, S. 221: „Daß Egon Bahr, mein damaliger Planungschef im Auswärtigen Amt, sich mit Jiři Hájek während eines Zwischenaufenthaltes in Frankfurt traf, war durch ein legitimes Informationsbedürfnis begründet. Aber aus alledem wurde abgrundtief Verwerfliches konstruiert." Brandt glaubt also trotz des Telegramms, daß das Gespräch stattgefunden hat.

121 Ebenda, S. $220 \mathrm{f}$.

122 Vgl. Guttenberg, Fußnoten, S. 96; siehe auch Hildebrand, Erhard, S. 337.

${ }^{123}$ AdKASt, Kiesinger I - 226, F/3., A 322, Gespräch mit Löwe, 31.1.1978, S. 14; dort auch die folgenden Zitate. 
sten Tag nach Prag. Kiesinger forderte entgeistert: „Sie müssen den Mann abbringen davon." Das erschwere doch die Position von Dubček, das liefere ihn doch geradezu ans Messer. Kiesinger fügte hinzu: „Und uns wird unsere ganze Politik zerstört. Wir erscheinen doch in der westlichen Welt als unglaubwürdig. Wir erscheinen doch als diejenigen, die mit dem Feuer spielen."124

Brandt sah diese Gefahr auch, aber er schien in begründeten Fällen nicht darauf verzichten zu wollen, durch Kontakte den Liberalisierungskurs in der ČSSR vorsichtig zu unterstützen. In den Erinnerungen weist er allerdings jeden Vorwurf an die Adresse der Sozialdemokraten zurück. Selbst Bestrebungen zur Wiedereinrichtung der tschechoslowakischen Sozialdemokratie - in kürzester Zeit waren dort über dreihundert örtliche Organisationen entstanden - seien in keiner Weise von der SPD ermutigt worden ${ }^{125}$. Brandt warb seinerseits auch auf anderen Feldern für Behutsamkeit im Umgang mit der ČSSR. Schon im Sommer, als die Bundeswehr ein Herbstmanöver in Grafenwöhr und Hohenfels direkt an der tschechischen Grenze plante, hatte der Außenminister den Kanzler gedrängt, dieses Manöver absagen zu lassen. Kiesinger brachte tatsächlich Verteidigungsminister Schröder noch im Juli dazu, die Truppenkonzentration an der Westgrenze der CSSR zu vermeiden und das Manöver an anderer Stelle, im Südwesten der Bundesrepublik, abzuhalten. Brandt reagierte auf diese Nachricht erleichtert ${ }^{126}$. Am 24. Juli schrieb er dem Kanzler: „Ich bin froh, daß Sie die Verteidiger dazu gebracht haben, die Septembermanöver von der tschechischen Grenze wegzuverlegen. "127 Auch die Tschechen fühlten sich durch die Verlegung von einer scheinbar schwer lastenden Sorge befreit. Die Mitglieder des Stadtausschusses Jeseniče, am südöstlichen Rand Prags gelegen, teilten in einem Brief beispielsweise mit: „Diese Erklärung sehen wir als Ausdruck Ihres empfindlichen Verständnisses für die Situation in CSSR an, und wir danken Ihnen dafür. " 128

Unterdessen waren Verhandlungen zwischen den Außenministerien beider Länder um die Aufnahme diplomatischer Beziehungen angelaufen. Ausgerechnet am 19. und 20. August befand sich eine tschechoslowakische Delegation in Bonn und erörterte mit Bahr die strittige Frage des Münchner Abkommens ${ }^{129}$. Die ČSSR drang darauf, die 1938 zwischen England, Frankreich, Italien und Deutschland vereinbarte Eingliederung des Sudetenlandes in das Deutsche Reich von Beginn an - ex tunc - für ungültig zu erklären ${ }^{130}$.

124 Ebenda, S. 15.

125 Vgl. Brandt, Erinnerungen, S. 221.

126 Der Verteidigungsminister hatte einige Zeit darauf beharrt, die Manöver doch an der Grenze stattfinden zu lassen. Brandt vermutete, Schröders Motiv liege in seiner Opposition zur Ostpolitik der Bundesregierung. In einem Interview hatte Schröder nämlich erklärt, die Ostpolitik habe sich als „trügerisch“ erwiesen; vgl. Der Spiegel, 29.7.1968, S. 20. Und Brandt beklagte sich gegenüber Kiesinger: Schröder werde von einem Teil der Presse in zunehmenden Maße für „eine Sonderposition in der Außenpolitik“ in Anspruch genommen. "Jedenfalls hat er unwidersprochen den Eindruck aufkommen lassen, als wünsche er sich von der Entspannungspolitik zu distanzieren." (AdKASt, Kiesinger I - 226, D/IV.6, A 001, Brandt an Kiesinger vom 30.7.1968, S. 3.) Kiesinger bestritt zumindest öffentlich, daß es im Kabinett unterschiedliche Auffassungen zu der Manöververlegung gegeben habe; vgl. Rheinische Post, 27.7.1968.

127 AdKASt, Kiesinger I - 226, D/IV.6, A 001, Brandt an Kiesinger vom 24.7.1968, S. 2.

128 AdKASt, Kiesinger I - 226, D/V.5, A 310, Z. Mašek an Kiesinger vom 5.8.1968.

$129 \mathrm{Vgl}$. Brandt, Begegnungen, S. 283; Brandt spricht allerdings nur von einem Tschechoslowaken, nicht von einer Delegation.

$130 \mathrm{Vgl}$. Frank, Entschlüsselte Botschaft, S. 304. Da der Vertrag „unter Druck“ zustande gekommen war, schlossen die Tschechoslowaken darauf, daß es sich um einen widerrechtlichen Akt des Deutschen Reiches handelte, mit dem der Zweite Weltkrieg begonnen hatte. Von dieser Interpretation leiteten sie einen Schadenersatzanspruch her. 
Die Bundesregierung beharrte dagegen auf einer anderen Sichtweise. Man könne nicht so tun, als ob der Vertrag niemals gegolten habe, auch wenn er später ungültig geworden sei, argumentierte das Auswärtige Amt. Doch unabhängig von diesem Meinungsunterschied mahnte der Planungschef im Auswärtigen Amt seine Prager Gesprächspartner zur Zurückhaltung. Mit Blick auf den tschechoslowakischen Wunsch, diplomatische Beziehungen zur Bundesrepublik schon im Jahr 1969 aufzunehmen, erklärte Bahr, er habe große Sorge, daß die Tschechoslowaken zu viel auf einmal und dies zu schnell wollten. Diese Bemerkung habe die Delegationsmitglieder aber aufgebracht, berichtete er später. Sie hätten kategorisch erklärt: „Das wissen wir besser, und da werden die Sowjets nichts machen." An einen Einmarsch glaubten sie nicht. Am nächsten Morgen hatte der Einmarsch begonnen. „Es war der 21. August, und da saßen die Leute fast weinend zusammen, und da hieß es dann, jetzt fahren Sie erst mal nach Hause. Ich glaube, da werden Sie jetzt gebraucht. Die Verhandlungen werden später fortgesetzt. " 131 Und tatsächlich seien die Verhandlungen erst 1973 wieder aufgenommen worden.

Die Bundesregierung kümmerte sich zunächst nicht darum, ob die Gespräche zwischen Bonn und Prag als Vorwand für die Intervention dienen konnten. Erst eine Woche nach der militärischen Aktion begann sie nach möglichen Unterlagen oder sonstigen Hinweisen zu suchen, die es der Sowjetunion ermöglichen und erleichtern würden, der Bundesrepublik die Schuld zu geben. Ende August forderte das Kanzleramt von Brandt, der sich in Genf aufhielt, eine Stellungnahme, ob den Sowjets irgendwelches geheimes Material in die Hände habe fallen können. Mit verschlüsseltem Fernschreiben schickte Brandt am 1. September eine keinesfalls beruhigende Lageeinschätzung zurück. Nach allem, was ihm bekannt sei, könne es keine kompromittierenden Unterlagen im Prager Außenministerium geben. Das schließe allerdings nicht aus, daß die Russen aus jeder Unterlage, die sie dort fänden, belastende Momente für die Bundesrepublik und die ČSSR konstruierten. Ein Treffen mit Außenminister Hajjek habe nicht stattgefunden und sei auch nicht beabsichtigt gewesen. Zum Stand der Verhandlungen über das Münchner Abkommen stellte Brandt fest, daß der Kanzler die Unterlagen der Gespräche Bahrs kenne. Im Fernschreiben faßte er den Diskussionsstand zusammen: „Das Problem ohne eine ex tunc-Ungültigkeitserklärung zu lösen, waren die Tschechen am Zug, Vorschläge zu machen. Derartige Vorschläge sind nicht mehr erfolgt. Wir haben damit im Amt auch allenfalls nach dem beabsichtigten Parteitag Anfang September gerechnet." 132

Außerdem versicherte Brandt, daß von einer Finanzierung der Sozialdemokratie in der ČSSR durch die SPD keine Rede sein könne. Allgemein sei den Tschechen mitgeteilt worden, daß Kreditwünsche von ihrer Seite „wohlwollend und ohne politische Bedingungen geprüft" würden. Aber da die Überlegungen über die Prager Wirtschafts- und Schwerpunktplanung noch nicht abgeschlossen gewesen seien, hätten keine Wünsche von tschechoslowakischer Seite vorgelegen. Brandt betonte am Schluß: „Für den Bereich des AA läßt sich insgesamt sagen, daß wir nicht den geringsten Grund haben, auf die wahrscheinlichen Vorwürfe sowjetischerseits zu reagieren, als hätten wir ein schlechtes Gewissen oder irgend etwas zu verbergen."

131 Bahr, Gespräch mit dem Verfasser, 4.7.1988.

132 AdKASt, Kiesinger I - 226, D/IV.6, A 001, Brandt an Kiesinger vom 1.9.1968; dort auch die folgenden Zitate. 


\section{Das Verbältnis zu Frankreich auf dem Tiefpunkt}

Da waren die Franzosen aber anderer Meinung. Der gerade vom Außen- zum Premierminister aufgerückte Maurice Couve de Murville behauptete, die Deutschen hätten mit ihren Kontakten und häufigen Besuchen die Sowjets in unnötiger Weise provoziert. Auch in seinen Memoiren hat er diese Ansicht später wiederholt ${ }^{133}$. De Gaulle fand, daß die Bundesregierung unverantwortlich gehandelt hatte. Für den Staatspräsidenten bedeutete der Einmarsch der Warschauer Pakttruppen das Ende seiner seit 1962 verfolgten Ostpolitik, die sich zum Ziel gesetzt hatte, die Blöcke in Europa langsam aufzulösen. Jetzt bekannte er offen seine Enttäuschung über die Bundesregierung. De Gaulle gab der Großen Koalition nicht nur die Mitschuld an der Intervention, sondern verargte den Deutschen auch, daß sie immer noch den Vorschlag Frankreichs ablehnten und sich einer Anerkennung der Oder-Neiße als Grenze verweigerten.

Wie sehr die gaullistische Ostpolitik von dieser Zustimmung Bonns abhing, hatte die französische Regierung erleben müssen, als sie im Januar 1968 vergeblich eine Initiative startete. Damals hielt sich der Finanz- und Wirtschaftsminister, zu diesem Zeitpunkt kurz bevor er zum Außenminister ernannt wurde - noch Debré, von der Öffentlichkeit kaum beachtet, im Rahmen der „großen französisch-sowjetischen Konsultationskommission“ in Moskau auf. Am 11. Januar traf er mit Kossygin zusammen. Debré soll dem sowjetischen Ministerpräsidenten eine Denkschrift de Gaulles überreicht haben. Der Staatspräsident, so wußten Zeitungen zu berichten, habe darin ein allgemeines europäisches Gewaltverzichtsabkommen vorgeschlagen ${ }^{134}$. Aber offenbar war der Kreml nicht auf den Vorschlag eingegangen. Moskau wollte den Gewaltverzicht allein mit der Bundesrepublik aushandeln. Die Erkenntnis, daß die Bundesregierung durch ihre eigene Ostpolitik plötzlich im Osten Interesse hervorrief, steigerte den Ärger de Gaulles. Dafür waren kleine Sticheleien ein Hinweis. Im Februar 1968 platzte ausgerechnet in die Einweihungsfeierlichkeiten des von den Franzosen an Deutschland zurückgegebenen Palais Beauharnais - der mit viel Aufwand wiederhergestellten früheren preußischen, dann der Botschafterresidenz des Deutschen Reiches in Paris - die Nachricht, Außenminister Brandt habe in Ravensburg über de Gaulles Konzept von den „uneuropäischen Gedanken eines machtbesessenen Regierungschefs “ gesprochen ${ }^{135}$. Obwohl der Minister hinterher die Äußerung bestritt, reagierte de Gaulle beleidigt und schroff. Die beiden Minister Schmücker und Wehner sowie der Staatssekretär im Auswärtigen Amt wurden kurzerhand von der Gästeliste für das am nächsten Morgen anberaumte Frühstück beim Staatspräsidenten gestrichen. Bundespräsident Lübke, so kritisierte Brandt später, habe sich das bieten lassen. Vermutlich seines hohen Alters wegen sei Lübkes Fähigkeit zu angemessener Reaktion wohl vermindert gewesen ${ }^{136}$. Brandt war der Meinung, daß der Bundespräsident ebenfalls hätte absagen müssen.

Darüber läßt sich streiten. In einem Brief vom 7. Februar rechtfertigte sich Lübke gegenüber dem Kanzler. Seine Absage, am Frühstück teilzunehmen, hätte dem deutsch-

133 Vgl. Couve de Murville, Außenpolitik, S. 232 f.

134 Vgl. Die Welt, 17.1.1968.

135 AdKASt, Kiesinger I -226, D/IV.6, A 001, Telegramm Kiesingers an Brandt vom 4.2.1968: „Nur für den Bundesminister. Nach einer DPA-Meldung sollen Sie am Samstag in Ravensburg mit Bezug auf de Gaulle von den ,uneuropäischen Gedanken eines machtbesessenen Regierungschefs ${ }^{*}$ gesprochen haben. $\mathrm{Da}$ ich nicht annehmen kann, daß Sie diese Äußerung getan haben, bitte ich Sie dringend um Berichtigung."

136 Vgl. Brandt, Erinnerungen, S. 241. 
französischen Verhältnis mehr geschadet als genutzt. Außerdem habe er sich sogleich für den deutschen Außenminister bei den französischen Gastgebern eingesetzt ${ }^{137}$. Die Affäre konnte beigelegt werden, doch der Ärger de Gaulles über die politische Haltung der Bundesregierung blieb und wandelte sich schließlich in Resignation. Kurz vor dem deutsch-französischen Konsultationstreffen im September 1968, dem ersten nach der sowjetischen Intervention in Prag, berief de Gaulle eine kleine Gruppe seiner engsten Berater zusammen. Dort stellte er eine ernüchternde Bilanz des Verhältnisses auf. Die Bundesrepublik und Frankreich befänden sich gegenüber der Sowjetunion nicht in der gleichen Lage, behauptete er. Deutschland habe den Krieg - „einen entsetzlichen Krieg“ verloren. Es sei geteilt, aber wolle die Folgen der Niederlage nicht hinnehmen. Die Russen haßten die Deutschen. Nichts davon gelte jedoch für Frankreich. Zwar verurteilte es ebenso wie die Bundesrepublik Deutschland die sowjetische Invasion in die Tschechoslowakei. „Wenn unser Nachbarland angegriffen würde, wären wir an seiner Seite. Aber Frankreich ist für die Entspannung und für den Frieden." Außerdem sei Frankreich mit der Bundesrepublik nicht zufrieden. Es habe von niemandem etwas gefordert. In den letzten Jahren sei es vorbildlich, zuweilen übertrieben großzügig gewesen. Was sei aber Deutschlands Gegenleistung? Bonn mache sich zum Fürsprecher des englischen Beitritts zur EWG, „wir dagegen widersetzen uns diesem Beitritt"138.

Die Gespräche am 27. und 28. September in Bonn fanden in einer bedrückten Atmosphäre statt, wie Botschafter Seydoux berichtet. Diese Stimmung habe auch bei den verschiedenen gesellschaftlichen Ereignissen geherrscht. „Fehlzündung“ habe ihm Debré nach den Tischreden im Kanzleramt am Abend des 27. September zugeraunt. De Gaulle habe sich in der Form verbindlicher als je zuvor, doch in der Sache strenger denn je geäußert ${ }^{139}$. Bei einem der beiden Vier-Augen-Gespräche machte der französische Staatspräsident dem Bundeskanzler Vorhaltungen wegen der deutschen Mitschuld an der tschechoslowakischen Tragödie. Aber der Kanzler wehrte sich; er verwies auf die Entgleisung, die de Gaulle im Vorjahr in Polen passiert war. „Nicht der deutsche Bundeskanzler, sondern der französische Staatspräsident ist es gewesen, der in Gdingen die Polen an ihre ruhmreiche Vergangenheit und ihre mögliche ruhmreiche Zukunft erinnert hat", sagte Kiesinger. Am Schluß habe de Gaulle ihn am Arm genommen: „Heute sind wir sehr rauh miteinander umgegangen. Jetzt wollen wir wieder freundlicher miteinander sein." 140

Das Gipfeltreffen hatte keine Wirkung auf das Verhältnis zwischen beiden Staaten. Die Bundesregierung ging in ihrer Ostpolitik nicht weiter als bisher, und sie beharrte auf dem Beitritt Englands zur EWG - ohne allerdings zu wissen, wie sie die Zustimmung der Franzosen dafür gewinnen sollte. Im Februar 1969 klagte Brandt Kiesinger einmal: „[...] es ist ein Jammer, daß wir es in der europäischen Zusammenarbeit so schwer haben. Ich sehe immer noch nicht, wie wir ernsthaft vorankommen können. Zunächst werde wir den Hauptpartnern gegenüber noch einmal vermeiden müssen, daß sich die Lage verschlimmert." 141

137 Vgl. AdKASt, Kiesinger I - 226, D/IV.6, A 006, Lübke an Kiesinger vom 7.2.1968, S. 1 f.

138 Seydoux, Botschafter in Deutschland, S. 145.

139 Vgl. Schmoeckel (Vergessene Regierung, S. 220), der meint, daß die Stimmung möglicherweise auch wegen der Mai-Unruhen in Paris so schlecht gewesen sei. De Gaulle habe sich deswegen so aggressiv und reizbar gezeigt.

140 AdKASt, Kiesinger I - 226, A 322, Gespräch mit Löwe, 31.1.1978, S. 15; vgl. auch Baring, Machtwechsel, S. 231, und Schmoeckel/Kaiser, Vergessene Regierung, S. 222.

${ }^{141}$ AdKASt, Kiesinger I - 226, D/IV.6, A 001, Brandt an Kiesinger vom 4.2.1969, S. 2. 
Tiefe Sorge über das Verhältnis beider Staaten zeigte im Januar 1969 ein Schreiben des französischen Hohen Kommissars und ersten Botschafters in Bonn, François-Poncet, das Kiesinger zur Kenntnisnahme übersandt wurde. Allmählich tauche in der krassesten Form in Frankreich der alte Nationalismus wieder auf. Alles bisher Erreichte scheine erneut in Frage gestellt, hieß es da ${ }^{142}$. Als de Gaulle am 27. April 1969, nach einer verlorenen Volksabstimmung, mit der er sein politisches Schicksal verbunden hatte, zurücktrat, schrieb ihm der Kanzler nach Colombey-les-deux-Églises, wohin sich de Gaulle ohne ein Wort des Abschieds zurückgezogen hatte. Kiesinger war sich des ungewöhnlichen Formats, der großen Persönlichkeit dieses Politikers immer bewußt gewesen. Daher hieß es in seinem Schreiben zum Ausscheiden aus dem Amt: „Ihr Entschluß, das Amt des Präsidenten der Französischen Republik niederzulegen, hat mich tief bewegt. Ihr Name und Ihr großes Werk sind in die Geschichte Frankreichs eingegangen. Aber auch das deutsche Volk dankt Ihnen, daß Sie weise und großherzig die Aussöhnung Frankreichs und Deutschlands vollendet haben. Ich werde die Gespräche, die ich mit Ihnen zu führen die Ehre hatte, in meiner Erinnerung bewahren. Ich wußte mich dabei mit Ihnen in der Überlegung einig, daß sich die europäischen Völker, ohne sich selbst aufzugeben, zu einem einigen Europa zusammenfinden müssen, das einen ehrenvollen Platz in dieser Welt einnehmen kann. Meine herzlichen Wünsche gelten in dieser ernsten Stunde der Zukunft Frankreichs, der Sie Ihr Leben gewidmet haben, der unzerstörbaren Freundschaft unserer beiden Völker und Ihrem persönlichen Wohlergehen." 143

Im Gedächtnis blieb Kiesinger, was de Gaulle einst in einer Tischrede in Bonn über das deutsch-französische Verhältnis in einem Gleichnis gesagt hatte. Er sprach von zwei Männern, die miteinander ausgezogen seien, um einen Schatz zu suchen. Nach müheund gefahrvoller Wanderung hätten sie erkennen müssen, daß sie weder Gold noch Edelsteine entdecken würden. Aber in diesem Moment erkannten sie etwas anderes, das für sie mehr bedeutete: Sie waren als Freunde heimgekehrt. Ihre Fähigkeit, gemeinsam zu handeln, ermöglichte es ihnen schließlich doch noch, Reichtum und Glück zu finden ${ }^{144}$.

\section{Folge der Intervention: Kiesinger versagt Brandt die Zustimmung zum Sperrvertrag}

Die Zerschlagung des Prager Frühlings führte neben der Belastung des deutsch-französischen Verhältnisses zu einem Stopp ostpolitischer Initiativen der Großen Koalition. Es gelang dem Kanzler, die Zustimmung zum Sperrvertrag bis auf die Zeit nach den Wahlen $1969 \mathrm{zu}$ verschieben. Obwohl dem Außenpolitiker deutlich war, daß die Ostpolitik nicht aufgegeben werden konnte, lähmte der Schock über den Einmarsch jede weitere Initiative ${ }^{145}$. Der Einmarsch untergrub das ohnehin geringe Vertrauen in die friedlichen Absichten der Sowjetunion. Würde sie versuchen, ihren Einfluß über den Ostblock hinaus nach Westen auszudehnen? Ihr Beharren auf dem Interventionsrecht der UN-Charta verhieß nichts Gutes. Man mußte befürchten, daß sie nach Möglichkeiten suchte, gegebenenfalls auch in West-Berlin oder sogar in Westdeutschland zu intervenieren. Die

142 Vgl. AdKASt, Kiesinger I - 226, D/IV.6, A 001, François-Poncet an den Verleger Franz Burda vom 25.1.1969.

143 AdKASt, Kiesinger I - 226, D/IV.6, A 003, Kiesinger an de Gaulle vom 30.4.1969.

144 Vgl. Oberndörfer (Hrsg.), Große Koalition, S. 92, Anmerkung.

145 Vgl. Hildebrand, Erhard, S. 337; Kiesinger erklärte bereits nach zwei Tagen, die Politik müsse fortgesetzt werden; Bahr hatte noch am 21.8. intern erklärt, daß sich mit dem abrupten Ende der Dubč ek-Ära die internationale Großwetterlage für Bonn nicht geändert habe; vgl. Baring, Machtwechsel, S. 231, und Schmoeckel/Kaiser, Vergessene Regierung, S. 220. Das Ereignis von Prag habe nicht abgeschreckt, aber „es ernüchterte“, schreibt Bender (Neue Ostpolitik, S. 154). 
alte Angst, die sowjetischen Kommunisten würden eines Tages die Bundesrepublik „kassieren“, wurde durch die militärische Aktion erneut wach. Brandt erklärte in seiner Rede am 3. September 1968 auf der Genfer Konferenz der Nichtkernwaffenstaaten, ohne Vertrauen auf gewisse Grundregeln des Zusammenlebens der Staaten gäbe es keine Kontrolle der zerstörerischen Kräfte, die der Kernenergie innenwohnten. Und er fügte hinzu: "Ohne solches Vertrauen gibt es keine internationale Ordnung.“" 146

Diese Sätze nahm Kiesinger wenige Wochen später auf, als er begründete, warum die Bundesregierung ihre Einwilligung zum Sperrvertrag zu diesem Zeitpunkt noch nicht geben könne ${ }^{147}$. Es bestehe nach den Ereignissen in Prag keine Notwendigkeit, die vielen problematischen Aspekte des NV-Vertrages zu behandeln, erklärte er am 25. September 1968 im Bundestag. Die Voraussetzungen für ein solches weitreichendes Abkommen seien nicht gegeben. Mit einem Schlag hatten die Sowjets dem Bundeskanzler von dem Druck befreit, eine Entscheidung rasch herbeiführen zu müssen ${ }^{148}$.

Auch Brandts Engagement für den Sperrvertrag schlief nach dem Prager Ereignis ein. Er ließ der innenpolitischen Diskussion jetzt ihren Lauf. Moskau war selbst schuld. Gegenüber dem Spiegel erklärte er: „Ich denke nach der tschechoslowakischen Krise nicht im Traum daran, mir die Beine auszureißen, sondern vertraue auf einen, wenn auch längere Zeit dauernden Prozeß der Klärung der Meinungen zu Hause. " ${ }^{149}$ Der Prozeß währte bis zum Ende der Koalition. Im Februar 1969 berichtete der Minister dem Kanzler, zum NV-Vertrag habe er sich „leidenschaftslos" geäußert. Man müsse abwarten, ob die Russen auf die Hinweise reagierten und ob die Amerikaner dabei helfen würden ${ }^{150}$. Brandt bezog sich auf einen Artikel, den er für das sozialdemokratische Organ Vorwärts ver$\mathrm{fa} \mathrm{At}$ hatte und der am 6. Februar erscheinen sollte. Es war ein nüchternes Plädoyer für eine Unterzeichnung des Vertrages durch die Bundesregierung. Ein einziges Gegenargument ließ der Minister allerdings gelten: den Widerstand gegen den sowjetischen Hinweis auf die andauernde Gültigkeit der Art. 53 und 107 der UN-Charta. Diese Artikel, stellte Brandt kategorisch fest, bildeten keine Rechtsgrundlage für eine Intervention. Sie seien „überständig“ und hätten keine praktische Bedeutung mehr. Darin sei man sich mit den Verbündeten einig, und diese hätten das der Sowjetunion gegenüber „ganz klargestellt". Trotzdem müsse die Bundesrepublik Wert darauf legen, daß in dieser Frage auch im Verhältnis zur Sowjetunion "nichts unausgesprochen “ bleibe, sondern daß "jede mögliche Klärung" herbeigeführt werde ${ }^{151}$.

Schließlich ließ auch der Druck aus den USA im Anschluß an die Ereignisse in der ČSSR nach, die Bundesrepublik zur Unterzeichnung zu drängen. Birrenbach, der im Auftrag des Kanzlers im September 1968 eine Informationsreise durch die Vereinigten Staaten unternahm, traf auf eine Regierung, die mit ihrer Außenpolitik ganz allgemein in die Defensive geraten war. Das Vietnam-Desaster zeichnete sich bereits ab. Der Unterstaatssekretär im State Department, Eugene Rostow, sagte Birrenbach, trotz des Interesses, das die Vereinigten Staaten an der Unterzeichnung des Nichtverbreitungsvertra-

146 EA 23 (1968), Folge 21, S. D 502 f.

147 Vgl. VdDB, 5. Wahlperiode, 185. Sitzung, Rede vom 25.9.1968, S. 10054.

148 Die CSU fühlte sich bestätigt. In einer Entschließung forderte sie politische und institutionelle Garantien für einen „atomaren Schutz vor Aggression und Erpressung“, bis die „Voraussetzungen für die Bildung eines integrierten europäischen Abschreckungspotentials erfüllt seien“; zitiert nach DzD, 1968, S. 1268.

149 Der Spiegel, 9.9.1968, S. 34.

150 AdKASt, Kiesinger I - 226, D/IV.6, A 001, Brandt an Kiesinger vom 4.2.1969, S. 2.

151 Brandt, Sperrvertrag und Gleichberechtigung, in: Vorwärts, 6.2.1969. 
ges durch die Bundesrepublik hätten, wolle man Bonn nicht dazu drängen. Auch der Senat hege inzwischen Zweifel am Sinn des Unternehmens, die Präsident und Außenminister allerdings zu zerstreuen suchten. Im übrigen erklärte Rusk, daß die Sowjetunion für den Rückschlag allein verantwortlich zu machen sei ${ }^{152}$.

Erst nach dem Amtsantritt der konservativen Administration von Präsident Richard Nixon im Januar 1969 verstärkte sich das amerikanische Werben um die deutsche Unterschrift wieder. Johnson hatte darauf verzichtet, für eine weitere Amtszeit zu kandidieren. Der republikanische Kandidat Nixon, Senator aus Kalifornien und Vizepräsident unter Eisenhower, trat seine Nachfolge an. Nixon, außenpolitisch versiert, berief Henry A. Kissinger, den deutsch-amerikanischen Harvard-Professor, zu seinem Nationalen Sicherheitsberater. Kissinger hatte die Regierung Johnson besonders wegen ihrer Deutschlandpolitik scharf kritisiert. Das Weiße Haus, erklärte er beispielsweise im Dezember 1966, behandle die Deutschen „rücksichtslos “153. Es bestehe, trotz deutscher Haushaltsprobleme, auf den Zahlungen im Rahmen der Truppenstationierungskosten, halte die Bundesregierung gleichzeitig zur Ostpolitik an und fordere obendrein von ihr die Unterzeichnung des Nichtverbreitungsvertrages. Am 8. Februar 1969 ließ der Sicherheitsberater dem Kanzler im Auftrag des Präsidenten allerdings die folgende vertrauliche Information übermitteln: „Er, Nixon, beurteile den NV-Vertrag skeptisch. Er selbst hätte den Vertrag nie so angestrebt und so verhandelt und geschlossen. Aber er müsse sich mit dem Erbe abfinden und im Interesse der Fortführung der amerikanischen Außenpolitik damit leben. Er sei überzeugt, daß es im deutschen Interesse liege, dem Vertrag beizutreten, da die bei einem Nichtbeitritt zu erwartenden außenpolitischen Nachteile die möglichen Vorteile um ein Vielfaches zu überwiegen drohten. Er werde Sie nie zur Unterschrift drängen, aber wolle Ihnen seine Auffassung offen darlegen. Mit Vertrauen und Zuversicht sehe er Ihrer Zusammenarbeit entgegen und freue sich sehr, Sie bald zu treffen." 154

$\mathrm{Zu}$ einer Unterschrift der Großen Koalition kam es dann nicht mehr. Dazu trug bei, daß die Sowjetunion, nachdem sie in ihrer Propaganda die Interventionsartikel der UNCharta beiseite ließ und nicht weiter erwähnte, erneut die Verurteilung des westdeutschen „revanchistischen“ Anspruchs auf West-Berlin in den Mittelpunkt rückte. Die Querelen um den Wahlort des Bundespräsidenten im Frühjahr 1969 und die immer stärker wahltaktisch motivierten Positionen der beiden großen Regierungsparteien verhinderten eine gemeinsame Haltung in dieser Sache. Von seiten der SPD brachte man das Thema nicht mehr auf, die Union verzichtete sowieso darauf. Die Verzögerungsstrategie hatte sich für Kiesinger ausgezahlt. Erst die sozialliberale Koalition unterschrieb den Kernwaffensperrvertrag schließlich am 28. November 1969, und erst 1974, also Jahre später, wurde er im Bundestag ratifiziert.

152 Vgl. Birrenbach, Meine Sondermissionen, S. 277; Baring, Machtwechsel, S. 231.

153 HIoWRP, Acc. 741058 M. 47/48, Box 83, Emmet an Kissinger vom 7.12.1966 nach einem Vortrag Kissingers: „[...] I fully share your present criticism of recklessness in pressing the Germans on the troop cost question, while at the same time we press for the detente policy and the nonproliferation treaty."

154 AdKASt, Kiesinger I - 226, D/IV.6, A 007, der deutsche Botschafter in Washington Rolf Pauls an Kiesinger vom 8.2.1969. 